\title{
Applications of Photonics in Agriculture Sector: A Review
}

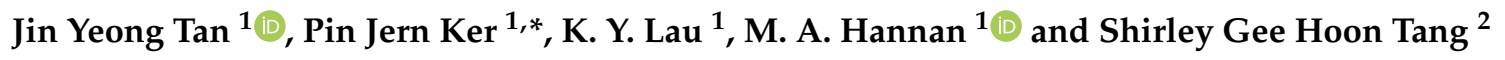 \\ 1 Institute of Power Engineering, College of Engineering, Universiti Tenaga Nasional, \\ Kajang 43000, Selangor, Malaysia; adrian_tan_jy@hotmail.com (J.Y.T.); kylau@uniten.edu.my (K.Y.L.); \\ Hannan@uniten.edu.my (M.A.H.) \\ 2 Microbiology Unit, Department of Pre-clinical, International Medical School, Management and Science \\ University, University Drive, Off Persiaran Olahraga, Seksyen 13, Shah Alam 40100, Selangor, Malaysia; \\ shirley_tang@msu.edu.my \\ * Correspondence: pinjern@uniten.edu.my
}

Received: 25 March 2019; Accepted: 12 May 2019; Published: 27 May 2019

\begin{abstract}
The agricultural industry has made a tremendous contribution to the foundations of civilization. Basic essentials such as food, beverages, clothes and domestic materials are enriched by the agricultural industry. However, the traditional method in agriculture cultivation is labor-intensive and inadequate to meet the accelerating nature of human demands. This scenario raises the need to explore state-of-the-art crop cultivation and harvesting technologies. In this regard, optics and photonics technologies have proven to be effective solutions. This paper aims to present a comprehensive review of three photonic techniques, namely imaging, spectroscopy and spectral imaging, in a comparative manner for agriculture applications. Essentially, the spectral imaging technique is a robust solution which combines the benefits of both imaging and spectroscopy but faces the risk of underutilization. This review also comprehends the practicality of all three techniques by presenting existing examples in agricultural applications. Furthermore, the potential of these techniques is reviewed and critiqued by looking into agricultural activities involving palm oil, rubber, and agro-food crops. All the possible issues and challenges in implementing the photonic techniques in agriculture are given prominence with a few selective recommendations. The highlighted insights in this review will hopefully lead to an increased effort in the development of photonics applications for the future agricultural industry.
\end{abstract}

Keywords: agriculture; photonics; imaging; spectral imaging; spectroscopy

\section{Introduction}

Light constitutes a collection of particles known as photons, propagated in the form of waves [1]. In physics, light often relates to radiation in the entire electromagnetic spectrum, encompassing X-rays, ultraviolet, visible light, infrared, and microwaves among others [2]. The unique electromagnetic properties of light have intrigued academics across the globe and the earliest study can be traced back to the early 17th century [3]. As time passes, the accumulation of knowledge and technological advancement have gradually shaped the canvas for light-related research, leading to the establishment of the field of optics and photonics.

Optics can be defined as a branch of physics that studies the behavior and properties of light as well as the interaction of light with other matter [2]. Meanwhile, photonics can be regarded as the application of light through the systematic generation, control and detection of photons [2,4]. Despite the distinction between optics and photonics, both terminologies have often been used interchangeably in the literature to collectively represent the science and application of light [1]. 
Optics and photonics have influenced various engineering applications, transforming the landscape of various fields and improving the lives of mankind. One of the main applications of optics and photonics can be seen in the field of communications. Knowledge of optics and photonics has been used to develop optical fibers which help to cater for the needs of broadband Internet service in this "data hungry" era. Furthermore, optics and photonics have been used in the manufacturing of modern displays such as liquid crystal display (LCD), organic light-emitting diode (OLED), flexible display and such. Solar cells for energy harnessing too illustrate another application of optics and photonics. Not least, optics and photonics have also been applied in more sophisticated areas such as security surveillance, medical imaging, quantum computing and more [1].

Amidst the modern and complex solutions discussed earlier, it often slipped our minds that optics and photonics can be readily integrated into the field of agriculture. The simplest examples would be the adjustment of plantation direction for optimum sunlight exposure, as well as the usage of incandescent light bulbs in egg incubation and hatching [5]. Over recent decades, academics have been alerted to the potential of optics and photonics in the agricultural industry. This has led to progressive developments that utilize optics and photonic techniques in maximizing the quality and productivity of agricultural products.

This paper aims to review some of the most popular optics and photonic techniques in agriculture, namely imaging, spectroscopy and spectral imaging. In addition, existing applications of each technique in the agricultural industry will also be compiled. A comprehensive discussion will also be made to gauge the potential of exploiting optics and photonic techniques in the agricultural sector with the intention of improving the quality and productivity of the agricultural products at a reduced labor cost.

\section{Classification of Photonics Systems in Agriculture}

Quantity and quality have always been the primary foci in the field of agriculture. The governing of these attributes is anticipated to be more crucial in the upcoming years. This prediction is based on the constant increase in global population as well as heightened expectations for healthy food sources. However, the agricultural field faces great pressure under globalization. The transformation of the global economic landscape makes agricultural activities seem less profitable in contrast to other industrial activities. The outflow of the workforce makes it increasingly expensive and difficult to meet the demands of agricultural activities.

As a result, modern technology has been integrated into the agricultural field to maximize output efficiency at minimum labor force. Similar to other industries, automation systems have been applied in stages of agricultural activities to reduce a dependency on manual labor [6]. These systems require optics and photonics techniques to complement them, providing the required 'sight' for operations. These vision requirements have been fulfilled by optics and photonic techniques such as imaging, and spectral imaging. These techniques provide machine vision at high dynamic range, high resolution and high accuracy in a non-destructive, non-contact and robust manner [5]. In the subsections below, details of ESS configurations, their classifications and structures have been illustrated.

\subsection{Imaging Technique}

The imaging technique is analogous to the function of the human eye. It captures the image of the subject for necessary calculations and measurements before performing the final evaluations [7]. The imaging technique is essential for collecting spatial, color [6] and even thermal [8] information of the subject of interest. Therefore, imaging techniques are typically operated in an active manner. The active imaging technique involves image acquisition under two major light sources, namely visible light and infrared sources. Images under visible light can be easily acquired with any standard camera modules. On the other hand, images under exposure to infrared can be acquired with special infrared camera modules [8]. 
Image acquisition under visible light is similar to our daily photography. The image acquisition process under this light source is straightforward and images captured are usually rich in details and colors. However, complexity often arises while performing analysis on these images due to illumination variations. For instance, images captured outdoors vary under sunny and cloudy conditions. Meanwhile, images captured indoors is categorized by natural light, incandescent and fluorescent conditions [7].

The acquired image will then undergo pre-processing to convert it into an appropriate format before further analysis. Pre-processing tasks may include exposure correction, color balancing, noise reduction, sharpness increase or orientation change. Next, the process of feature detection and matching as well as segmentation is performed on the pre-processed image to extract the object or region of interest. Finally, the subject of interest is analyzed with proper analysis algorithms in the respective area of application [9].

The imaging technique can be easily applied in the simple analysis of static-positioned objects or even in more complex areas which involve moving targets, such as visual navigation and behavioral surveillance. These achievements were made possible by utilizing the spatial information acquired through the imaging technique for position triangulation and motion guidance [7,9]. In image processing, the computer imaging technique has been employed to create, edit, and display graphical images, characters, and objects. The computer image analysis technique is a broad field which consists of computer domains and applications in food quality evaluation $[10,11]$, grading and the sorting of agricultural products [12,13], as well as harvesting the crops [14], and estimating moisture content in the drying stage for the storability of the food product [15]. Computer imaging contributes to the development of digital agriculture. For instance, weed detection and fruit grading systems with digital imaging techniques are cost effective systems in achieving ecological and economically sustainable agriculture [16].

\subsection{Spectroscopy Technique}

In contrast to the imaging technique, the spectroscopy technique enables the 'sight' of properties that are invisible to the naked eye. The spectroscopy technique functions by extracting spectral information from the sample of interest. The spectral information is obtained when light interacts with the composition of the sample. This interaction leads to changes in the intensity or frequency and wavelength of the initial light source, ultimately defining a spectrum which acts as the fingerprint of the sample [17].

Similar to the imaging technique, variations do exist for spectroscopy. These variations are categorized by the nature of interaction between the light source and the sample when the spectroscopy measurement is conducted. In the agricultural field, the commonly adopted spectroscopy techniques are ultraviolet-visible (UV-VIS) spectroscopy, fluorescence spectroscopy, infrared (IR) spectroscopy, and Raman spectroscopy [17].

\subsubsection{Ultraviolet-Visible (UV-VIS) Spectroscopy}

The ultraviolet-visible (UV-VIS) spectroscopy is conducted in both the ultraviolet (UV) and visible light (VIS) band, spanning wavelengths from $100 \mathrm{~nm}$ to $380 \mathrm{~nm}$ (UV) and from $380 \mathrm{~nm}$ to $750 \mathrm{~nm}$ (VIS). The principle governing the UV-VIS spectroscopy is Beer-Lambert's law, which is expressed by (1) and (2):

$$
\begin{gathered}
I=I_{0} 10^{-\varepsilon c l}, \\
\ln \frac{I_{0}}{\mathrm{I}}=\ln \frac{1}{T}=\varepsilon c l=A
\end{gathered}
$$

where $I_{0}$ and $I$ are intensity of light entering and leaving a sample respectively, $\varepsilon$ is the extinction molar coefficient, $c$ is the molar concentration of substance, $l$ is the thickness of sample $(\mathrm{cm}), T$ is transmittance and $A$ is absorbance [18].

A typical model that illustrates Beer-Lambert's law can be seen in Figure 1. It can be observed that as light propagates through a sample, a portion of the incidental light source will be absorbed by 
the molecules in the sample, while the remaining light rays will transmit and escape across the sample. The ratio between the intensity of the incident and escaped rays defines the absorbance of light by the sample. This value of light absorbance is of main interest in UV-VIS spectroscopy. As in Equation (2), light absorbance is dependent on $\varepsilon, c$, and $l$ [18]. The absorbance value(s) at a single or multiple wavelength(s) will then be used to measure the concentration of compounds in a sample [19-23].

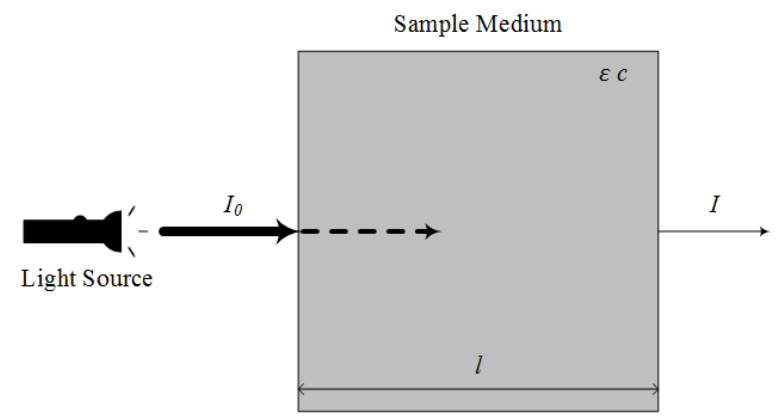

Figure 1. Model of Beer-Lambert's Law [18].

\subsubsection{Fluorescence Spectroscopy}

Fluorescence spectroscopy is distinct from other spectroscopy techniques in terms of the emission of light when incident rays from an ultraviolet or visible light source is absorbed by fluorescent molecules present in a sample. These fluorescent molecules are known as fluorophores and commonly known examples include quinine, fluorescein, acridine orange, rhodamine B and pyridine 1 [24].

The fluorescence phenomenon can be explained with a Jablonski diagram illustrated in Figure 2. It should first be understood that fluorescence involves the three electronic states of a fluorophore molecule, namely the singlet ground, first and second electronic states. These states are represented by $S_{0}, S_{1}$ and $S_{2}$ in Figure 2. The key condition for fluorescence to occur is the excitation of the molecule from the ground state, $S_{0}$ to either electronic states $S_{1}$ or $S_{2}$ upon the absorption of light. If the molecule reaches the $S_{2}$ state, internal conversion or vibrational relaxation will occur, returning the molecule to the lower $S_{1}$ state without radiation emitted. From here, the molecule will again return to the $S_{0}$ while emitting light which has equal energy as the energy difference between $S_{0}$ and $S_{1}$. This light emission is known as fluorescence and this condition typically occurs $10^{-8}$ seconds after the initial excitation [17].

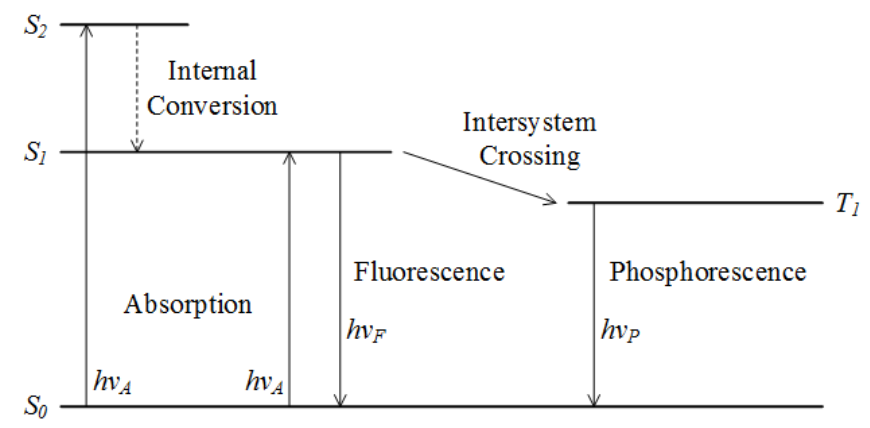

Figure 2. Jablonski diagram [17]. Reproduced with permission from A. Nawrocka, Advances in Agrophysical Research, Published by IntechOpen, 2013.

Fluorescence spectroscopy is highly specific and highly sensitive. The high specificity of the technique arises from the usage of both the excitation and emission spectra; whereas high sensitivity is achieved as radiation measurements are made against absolute darkness. These characteristics however limit the independent usage of the technique [17]. As a result, fluorescence spectroscopy is often combined with high performance liquid chromatography (HPLC) [25]. Variations may also be implemented in the excitation and emission wavelengths, forming the synchronous fluorescence spectroscopy (SFS) [26]. 


\subsubsection{Infrared (IR) Spectroscopy}

Infrared (IR) spectroscopy operates within the IR band with wavelengths from $780 \mathrm{~nm}$ to $1 \mathrm{~mm}$. The IR band can be further broken down into three sub-bands, namely near-infrared (NIR; $780 \mathrm{~nm}$ to $5 \mu \mathrm{m}$ ), mid-infrared (MIR; $5 \mu \mathrm{m}$ to $30 \mu \mathrm{m}$ ) and far-infrared (FIR; $30 \mu \mathrm{m}$ to $1 \mathrm{~mm}$ ). In agriculture-related optics and photonics, the NIR and MIR bands are of greater interest [17].

IR spectroscopy obtains the spectral information of a subject due to molecular vibrations under the excitation of an IR light source. In general, molecular vibrations occur when there exist normal modes of vibrations. A normal mode of vibration (or fundamental) refers to the phenomenon in which every atom in a molecule experiences a simple harmonic oscillation about its equilibrium position. These atoms oscillate in phase at the same frequency while the center of gravity of the molecule remains unchanged. A typical molecule has $3 \mathrm{~N}-6$ fundamentals (3N-5 for linear molecules), where $\mathrm{N}$ refers to the number of atoms. The diatomic molecular vibrations are illustrated in Figure 3 [27].

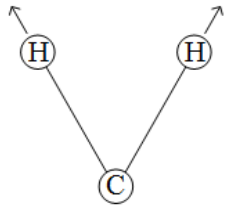

(a) Symmetrical Stretching

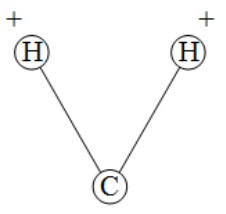

(d) Wagging

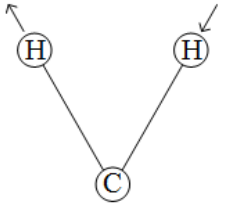

(b) Anti-symmetrical Stretching

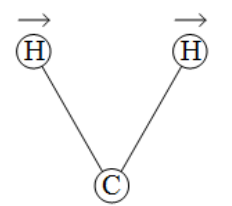

(e) Rocking

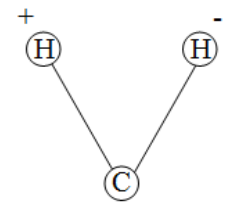

(c) Twisting

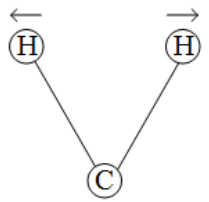

(f) Scissoring

Figure 3. Vibrations in diatomic molecules [17]. Reproduced with permission from A. Nawrocka, Advances in Agrophysical Research, Published by IntechOpen, 2013.

Molecular vibrations, which occur regardless the presence of IR light source, result in an increase in light absorption. These peaks in absorption form specific bands in the IR spectrum that correspond to the specific frequencies in which molecular vibrations occur. This allows the easy identification of the molecular structure in a sample since different molecules have different vibration frequencies [27]. This unique frequency 'fingerprint' is exceptionally beneficial in the analysis of complex molecules that contains functional groups such as $-\mathrm{OH},-\mathrm{NH}_{2},-\mathrm{CH}_{3}, \mathrm{C}=\mathrm{O}, \mathrm{C}_{6} \mathrm{H}_{5^{-}}$and more. For instance, the $\mathrm{C}_{6} \mathrm{H}_{5}$ - group forms peaks at wavenumbers from $1600 \mathrm{~cm}^{-1}$ to $1500 \mathrm{~cm}^{-1}$ (wavelengths from $6.25 \mu \mathrm{m}$ to $6.67 \mu \mathrm{m}$ ) whereas the $\mathrm{C}=\mathrm{O}$ group exhibits high absorption at wavenumbers from $1800 \mathrm{~cm}^{-1}$ to $1650 \mathrm{~cm}^{-1}$ (wavelengths from $5.56 \mu \mathrm{m}$ to $6.06 \mu \mathrm{m}$ ) [28].

\subsubsection{Near-Infrared (NIR) Spectroscopy}

The near-infrared (NIR) spectroscopy operates within the NIR band with wavelengths from $780 \mathrm{~nm}$ to $5 \mu \mathrm{m}$. The absorptions within the NIR band exist due to overtones and combinations of the fundamental vibrations. Overtones refer to higher frequencies that are multiples of the fundamental frequency. Meanwhile, combinations involve interactions between two or more vibrations occurring simultaneously, resulting in a frequency which is the sum of multiples of the respective frequencies. A majority of the absorptions in the NIR band are due to vibrations of the $\mathrm{C}-\mathrm{H}, \mathrm{O}-\mathrm{H}$ and $\mathrm{N}-\mathrm{H}$ bands. The $\mathrm{S}-\mathrm{H}$ and $\mathrm{C}=\mathrm{O}$ bonds too potentially contribute to these absorptions. Several assignments of the NIR absorption bands can be seen in Table 1 [29]. 
Table 1. Examples of NIR absorption bands [29].

\begin{tabular}{|c|c|c|}
\hline Wavelength (nm) & Wavenumber $\left(\mathrm{cm}^{-1}\right)$ & Assignment \\
\hline & & Water \\
\hline 1454 & 6878 & 1st overtone $\mathrm{O}-\mathrm{H}$ stretching \\
\hline \multirow[t]{2}{*}{1932} & 5176 & $\mathrm{O}-\mathrm{H}$ combination \\
\hline & & Proteins \\
\hline 1208 & 8278 & 2nd overtone $\mathrm{C}-\mathrm{H}$ stretching \\
\hline 1465 & 6826 & 1st overtone $\mathrm{N}-\mathrm{H}$ and $\mathrm{O}-\mathrm{H}$ stretching \\
\hline 1734 & 5767 & 1st overtone $\mathrm{C}-\mathrm{H}$ stretching \\
\hline 1932 & 5176 & \multirow{3}{*}{$\mathrm{N}-\mathrm{H}$ combination and $\mathrm{O}-\mathrm{H}$ stretching } \\
\hline 2058 & 4859 & \\
\hline 2180 & 4587 & \\
\hline 2302 & 4344 & \multirow{2}{*}{$\mathrm{C}-\mathrm{H}$ stretching combination } \\
\hline \multirow[t]{2}{*}{2342} & 4270 & \\
\hline & & Oil \\
\hline 1210 & 8264 & 2nd overtone $\mathrm{C}-\mathrm{H}$ stretching \\
\hline 1406 & 7112 & 1st overtone $\mathrm{N}-\mathrm{H}$ and $\mathrm{O}-\mathrm{H}$ stretching \\
\hline 1718 & 5821 & \multirow{2}{*}{ 1st overtone $\mathrm{C}-\mathrm{H}$ stretching } \\
\hline 1760 & 5682 & \\
\hline 2114 & 4730 & $\mathrm{~N}-\mathrm{H}$ combination and $\mathrm{O}-\mathrm{H}$ stretching \\
\hline 2308 & 4333 & \multirow{2}{*}{$\mathrm{C}-\mathrm{H}$ stretching combination } \\
\hline \multirow[t]{2}{*}{2346} & 4263 & \\
\hline & & Starch \\
\hline 1204 & 8306 & 2nd overtone $\mathrm{C}-\mathrm{H}$ stretching \\
\hline 1464 & 6831 & 1st overtone $\mathrm{N}-\mathrm{H}$ and $\mathrm{O}-\mathrm{H}$ stretching \\
\hline 1932 & 5176 & $\mathrm{~N}-\mathrm{H}$ combination and $\mathrm{O}-\mathrm{H}$ stretching \\
\hline 2100 & 4762 & \\
\hline 2290 & 4367 & $\mathrm{C}-\mathrm{H}$ stretching combination \\
\hline 2324 & 4303 & \\
\hline
\end{tabular}

NIR spectroscopy, which is a non-destructive measurement, enables the simultaneous identification of components in a single sample within a short period of time, making it a preferable replacement for various chemical techniques. However, consideration should be taken into account as this technique requires initial calibration with samples of known composition, requiring great expenses of time and resources. Not least, frequent recalibration and issue of instrument interoperability might affect the practicality of the NIR spectroscopy technique [29].

\subsubsection{Mid-Infrared (MIR) Spectroscopy}

The mid-infrared (MIR) spectroscopy operates within the MIR band with wavelengths from $5 \mu \mathrm{m}$ to $30 \mu \mathrm{m}$ (wavenumbers from $4000 \mathrm{~cm}^{-1}$ to $400 \mathrm{~cm}^{-1}$; note the presence of slight overlapping with NIR). The absorptions that occur within the MIR band are due to fundamental vibrations and can be segregated into four regions, namely the $X-H$ stretching region $\left(4000 \mathrm{~cm}^{-1}\right.$ to $\left.2500 \mathrm{~cm}^{-1}\right)$, triple-bond region $\left(2500 \mathrm{~cm}^{-1}\right.$ to $\left.2000 \mathrm{~cm}^{-1}\right)$, double-bond region $\left(2000 \mathrm{~cm}^{-1}\right.$ to $\left.1500 \mathrm{~cm}^{-1}\right)$ as well as the fingerprint region $\left(1500 \mathrm{~cm}^{-1}\right.$ to $\left.600 \mathrm{~cm}^{-1}\right)$ [27].

The $\mathrm{X}-\mathrm{H}$ stretching region is due to vibrations from $\mathrm{O}-\mathrm{H}, \mathrm{C}-\mathrm{H}$ and $\mathrm{N}-\mathrm{H}$ stretching. The triple-bond region arises from vibrations of $\mathrm{C} \equiv \mathrm{C}$ and $\mathrm{C} \equiv \mathrm{N}$ bonds. Besides, the double-bond region relates to $\mathrm{C}=\mathrm{C}$, 
$\mathrm{C}=\mathrm{O}$ and $\mathrm{C}=\mathrm{N}$ vibrations. Lastly, the fingerprint region roots on bending and skeletal vibrations. Table 2 lists some of the common examples of MIR absorption bands [27].

Table 2. Examples of MIR absorption bands [27].

\begin{tabular}{ccc}
\hline Wavelength $(\mathbf{n m})$ & Wavenumber $\left.\mathbf{( c m}^{-\mathbf{1}}\right)$ & Assignment \\
\hline $2.778-3.125$ & $3200-3600$ & Water \\
\hline 6.061 & 1650 & O-H stretching \\
\hline $5.917-6.250$ & $1600-1690$ & Proteins \\
\hline $6.349-6.757$ & $1480-1575$ & Amide II (C-N stretching and N-H bending) \\
\hline $7.692-8.130$ & $1230-1300$ & Amide III (C-N stretching and N-H bending) \\
\hline $3.333-3.571$ & & Fats \\
\hline $5.731-5.797$ & $2800-3000$ & C-H stretching \\
\hline 10.309 & $1725-1745$ & C=O stretching \\
\hline $3.333-3.571$ & 970 & C=C-H bending \\
\hline $7.143-12.500$ & $2800-3000$ & Carbohydrates \\
\hline
\end{tabular}

MIR spectroscopy is effective since it provides information on structure-function relationships while performing quantitative analysis. The structure-function relationships are useful in food research and quality control, making MIR spectroscopy a crucial technique in the field of agriculture. The Fourier transform process is often bundled with MIR spectroscopy for data analysis, forming the popular Fourier transform infrared spectroscopy (FTIR) technique [27].

\subsubsection{Raman Spectroscopy}

Raman spectroscopy (RS), similar to IR spectroscopy, is another form of vibrational spectroscopy technique. RS obtains the spectral information of samples due to the occurrence of Raman effects [30]. Prior to understanding the Raman effects, one should look into the light scattering schemes that occur when incident photons interact with molecules in the sample. The possible light scattering schemes are illustrated in Figure 4. In the case of elastic scattering or Rayleigh scattering, the excited photons experience no change in energy content upon returning to ground state. Alternately, in the case of inelastic scattering or Raman scattering, the excited photons may lose (Stokes' shift) or gain (Anti-Stokes' shift) energy equivalent to the vibrational energy changes in the atoms of the molecules. This affects the motion of the atoms as well as the polarizability of the molecule. The change in molecule polarizability results in increased Raman intensity, ultimately forming the Raman spectrum when plotted across the investigated wavenumbers. However, this effect is weak as the probability of energy exchange is low [30].

The RS technique is gaining popularity as it enables the identification of molecular structure through the characteristic wavenumber in which vibrations occur. Furthermore, samples can be studied in the absence of a solvent as water causes weak Raman scattering. Not least, this technique is instantaneous and may undergo intensity enhancement. However, this technique is not without limitations. Due to the low probability of Raman scattering, this technique requires high concentration of samples. Moreover, sample molecules may experience photo degradation due to excitation of electronic absorption bands. The existence of fluorescence from impurities may disrupt the results 
obtained as well. These limitations aside, the RS technique can be combined with IR spectroscopy to deliver satisfactory results as summarized in Table 3 [30].

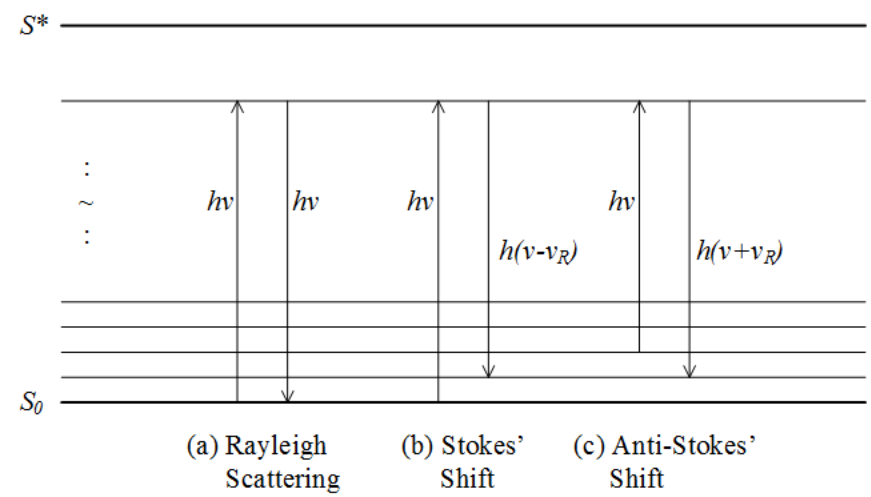

Figure 4. Light scattering schemes [17]. Reproduced with permission from A. Nawrocka, Advances in Agrophysical Research, Published by IntechOpen, 2013.

Table 3. Examples of Raman bands [30].

\begin{tabular}{|c|c|c|}
\hline Wavelength (nm) & Wavenumber $\left(\mathrm{cm}^{-1}\right)$ & Assignment \\
\hline & & Water \\
\hline \multirow[t]{2}{*}{$2.778-3.125$} & $3200-3600$ & $\mathrm{O}-\mathrm{H}$ stretching \\
\hline & & Proteins \\
\hline 19.608 & 510 & \\
\hline 19.048 & 525 & S-S stretching \\
\hline 18.349 & 545 & \\
\hline $14.925-15.873$ & $630-670$ & $C \mathrm{~S}$ ctrotching \\
\hline $13.423-14.286$ & $700-745$ & $C \rightarrow$ stretcning \\
\hline $5.882-6.250$ & $1600-1700$ & Amide $\mathrm{I}(\mathrm{C}=\mathrm{O}$ stretching and $\mathrm{N}-\mathrm{H}$ bending $)$ \\
\hline $8.032-8.097$ & $1235-1245$ & Amide III (C-N stretching and $\mathrm{N}-\mathrm{H}$ bending) \\
\hline $3.876-3.922$ & $2550-2580$ & S-H stretching \\
\hline \multirow[t]{2}{*}{$3.333-3.571$} & $2800-3000$ & $\mathrm{C}-\mathrm{H}$ stretching \\
\hline & & Fats \\
\hline 6.940 & 1441 & $\mathrm{CH}_{2}$ bending \\
\hline 6.863 & 1457 & $\mathrm{CH}_{3}-\mathrm{CH}_{2}$ bending \\
\hline 6.039 & 1656 & $\mathrm{C}=\mathrm{C}$ stretching \\
\hline \multirow[t]{2}{*}{$3.378-3.503$} & $2855-2960$ & $\mathrm{C}-\mathrm{H}$ stretching \\
\hline & & Carbohydrates \\
\hline 11.962 & 836 & $\mathrm{C}-\mathrm{C}$ stretching \\
\hline 9.398 & 1064 & $\mathrm{C}-\mathrm{O}$ stretching \\
\hline 3.434 & 2912 & $C$ \\
\hline 3.397 & 2944 & $\mathrm{C}-\mathrm{H}$ stretching \\
\hline 2.898 & 3451 & O-H stretching \\
\hline
\end{tabular}

\subsubsection{Additional Spectroscopy Techniques}

Apart from the popular spectroscopy techniques discussed earlier, existing studies presented additional variations of spectroscopy techniques which may be more complex in nature. For instance, dielectric spectroscopy has been utilized in agricultural inspections. Dielectric spectroscopy involves the inspection of dielectric properties or permittivity of samples over broad frequency ranges. Dielectric 
properties or permittivity refers to the ability of samples to store electrical energy in the electric field. In this spectroscopy technique, the permittivity is a complex permittivity relative to the free space, and this complex number is represented by (3):

$$
\varepsilon=\varepsilon^{\prime}+\mathrm{j} \varepsilon^{\prime \prime}
$$

where the real part, $\varepsilon^{\prime}$, is the dielectric constant and the imaginary part, $\varepsilon^{\prime \prime}$, is the dielectric loss factor which covers losses due to dipolar relaxation and ionic conduction [31]. Another spectroscopy variation is the nuclear magnetic resonance (NMR) spectroscopy technique. The NMR spectroscopy gains spectral information of samples from the interaction between the magnetic moments of nuclei of various atoms and the applied magnetic fields. The two common phenomena that give rise to the NMR spectra are chemical shift and J-coupling [32].

A chemical shift occurs due to different resonant frequencies present in nuclei of the same species. The difference in resonant frequencies is a result of shielding effect from electrons surrounding the nuclei. The shielding effect is sensitive to chemical environments, hence allowing the characteristic identification of specific molecular functional groups [32].

The J-coupling phenomenon is also known as indirect (scalar) spin-spin coupling. This coupling effect results in splitting of spectroscopic lines into multiplets. The J-coupling occurs between two nuclei or groups of nuclei and is governed by the polarization of electrons on the chemical bonds connecting these nuclei. The polarization scheme is in turn dependent on the instant orientation of the nuclear magnetic moments in the presence of a magnetic field [32].

\subsubsection{Spectroscopy Processing and Analysis}

The raw spectral data undergoes pre-processing or pre-treatment in order to reduce noise and correct baseline variations. The common pre-treatment techniques are multiplicative scattering correction (MSC), standard normal variate (SNV), Savitzky-Golay smoothing as well as first and second derivatives $[33,34]$.

Upon the completion of pre-processing or pre-treatment, the data set undergoes multivariate analysis to select and extract wavelengths that contain useful information. This aids in rectifying issues of collinearity, band overlapping and interaction between spectral variables. The results from multivariate analysis will be used to develop calibration models for calibration and prediction purposes [33,34].

The developed calibration models can be categorized according to the nature of the utilized multivariate analysis such as linear regression or nonlinear regression. Calibration models based on linear regression are built from partial least squares (PLS), interval partial least squares (iPLS), synergy interval partial least squares (SiPLS) or successive projections algorithm (SPA). Meanwhile, calibration models based on nonlinear regression are constructed from principal component analysis (PCA), independent component analysis (ICA), support vector machines (SVM), artificial neural networks (ANN) or a genetic algorithm (GA) [33,34].

The robustness of the final calibration model is evaluated from its ability to perform calibration and prediction. The calibration performance of the model is determined from the root mean square error of calibration (RMSEC) and the correlation coefficient $\left(\mathrm{R}_{\mathrm{C}}\right)$ in the calibration set. Meanwhile, the prediction performance of the model is identified from the root mean square error of prediction (RMSEP) and the correlation coefficient $\left(\mathrm{R}_{\mathrm{P}}\right)$ in the prediction set. Ideally, an effective model should register low RMSEC and RMSEP, with minimum difference between RMSEC and RMSEP. Not least, higher $R_{C}$ and $R_{P}$ are preferable $[33,34]$.

\subsection{Spectral Imaging Technique}

The spectral imaging technique is a combination of both imaging and spectroscopy techniques discussed earlier. Being a combinational technique, the spectral imaging technique preserves the best 
of both worlds, allowing the simultaneous extraction of spatial and spectral information from the inspected sample $[35,36]$.

\subsubsection{Classes of Spectral Imaging}

The spectral imaging technique acquires multiple images of the same subject at varying wavelengths. The resulting spectral images are three-dimensional (3-D) in nature, consisting of two spatial dimensions (row, $x$, and column, y) and one spectral dimension (wavelength, $\lambda$ ). Variations of spectral imaging technique are determined by the continuity of data in the wavelength dimension, branching out into hyperspectral imaging and multispectral imaging [35,36].

In general, hyperspectral imaging obtains spectral images in continuous wavelengths, whereas multispectral imaging registers spectral images at discrete wavelengths. Hyperspectral imaging acquires large number of images at high spatial and spectral resolutions. Due to the high volume of data, hyperspectral imaging requires long image acquisition time and involves complex algorithms for image analysis. Despite the complexity, hyperspectral imaging is essential for fundamental research and is the basis for multispectral imaging [35,36].

Multispectral imaging acquires spectral images at a significantly smaller number compared to hyperspectral imaging. Spectral images will only be acquired at optimal wavelengths predetermined from the analysis of dataset obtained through hyperspectral imaging. A smaller number of interested wavelengths allows rapid image acquisition and requires simpler image analysis algorithms. This characteristic of optimum data volume makes multispectral imaging perfectly suited for real-time in-field applications $[35,36]$.

\subsubsection{Spectral Image Acquisition Methods}

There are several methods in which spectral imaging systems acquire spectral images. The methods are point scan, line scan and area scan as illustrated in Figure 5 [35]. The point scan (whiskbroom) method acquires the spectrum of a single pixel in each scan. A complete hyperspectral cube will be generated as the detector moves from pixel to pixel along the two spatial axes ( $x$ and $y$ ). The point scan method is similar to a normal spectroscopic approach. Since it cannot cover a large sample area, the point scan method is time consuming and unsuitable for fast image acquisition [35,36].

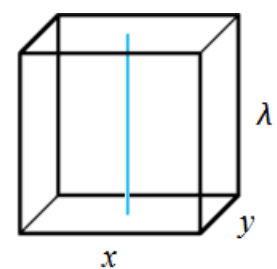

(a)

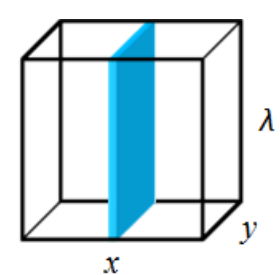

(b)

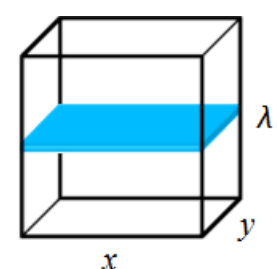

(c)

Figure 5. Methods of spectral image acquisitions with (a) point scan, (b) line scan, and (c) area scan [35]. Reproduced with permission from J. Qin, Journal of Food Engineering, Published by Elsevier, 2013.

The line scan (pushbroom) method, in each scan, acquires a slit (line) of spatial information together with the spectrum of every pixel along the line. A complete hyperspectral cube will be formed when scans are repeated along the direction of motion $(x)$. The operation characteristic of the line scan method makes it suitable to acquire spectral images of moving samples. Hence, this method is usually combined with conveyor belt systems, making it a popular method in practical production lines. However, the exposure time should be short and accurately selected to allow uniform exposure at all wavelengths $[35,36]$. 
The area scan (band sequential) method, on the other hand, acquires a 2-D grayscale image comprising of complete spatial information in a single wavelength. A complete hyperspectral cube is generated through image stacking when scans are performed along the spectral axis $(\lambda)$. The nature of the area scan method makes it more suited for the imaging of stationary samples instead of moving samples. In short, among the image acquisition methods discussed, line scan and area scan are greatly preferred over point scan for both hyperspectral and multispectral imaging on the basis of time consumption $[35,36]$.

\subsubsection{Spectral Imaging Sensing Modes}

Spectral imaging may have varying sensing modes as illustrated in Figure 6. The sensing modes are determined by the positions of the light source and the detector, forming variations such as reflectance, transmittance and interactance modes. In reflectance mode, the detector collects the light reflected off the illuminated surface. This sensing mode is suitable for identifying external features of samples such as size, shape, color, texture and defects. However, when selecting this mode, the detector should be properly positioned to avoid specular reflection [36].

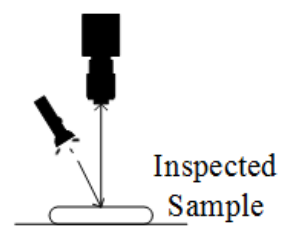

(a)

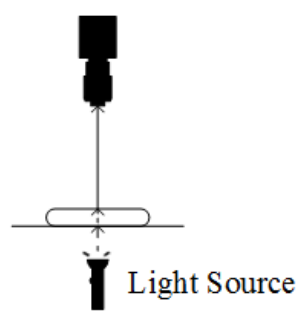

(b)

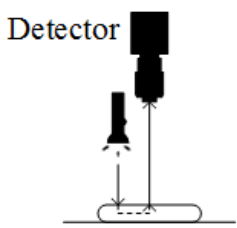

(c)

Figure 6. Sensing modes in spectral imaging; (a) reflectance, (b) transmittance, and (c) Interactance [36]. Reproduced with permission from D. Wu, Innovative Food Science \& Emerging Technologies, Published by Elsevier, 2013.

The transmittance mode operates by having the detector collect light rays transmitted through inspected samples. In this sensing mode, the light source and the detector will be placed in opposite direction to each other. Due to the absorption of light rays in a sample, the detected signal will be relatively weak and dependent on sample thickness. Hence, the transmittance mode is commonly applied in the internal inspection of relatively transparent samples [36].

Meanwhile, the interactance mode overcomes the limitations of both the reflectance and transmittance modes. This sensing mode exhibits less surface effect compared to reflectance mode. At the same time, it allows detection in deeper layers of a sample without being affected by sample thickness as in transmittance mode. This advantageous sensing mode is set up by installing the light source and the detector at the same side and parallel to each other [36].

\subsubsection{Spectral Imaging System Construction}

The variations in spectral imaging lead to a diversity of instruments during the construction of a spectral imaging system. In general, a spectral imaging system is made up of a light source, a wavelength dispersive device and an area detector [35,36].

The light source for a spectral imaging system can be classified into illumination and excitation sources. Illumination light source is selected when measurements involve changes in the intensity of the incident rays upon light-sample interaction. The spectral composition of the incident source will not experience any changes. Such interaction is commonly observed in reflectance and transmittance sensing modes. Broadband lights are normally used as illumination sources. An example of illumination light source is the quartz tungsten halogen (QTH) lamp which is capable of generating a smooth 
spectrum in the visible to infrared range. Besides, the broadband light emitting diode (LED) has gained popularity over time due to its low power consumption, low heat generation, small size and long lifetime $[35,36]$.

Excitation light source is usually selected when measurements involve changes in the frequency and wavelength of the incident rays. Interactions of this nature usually involve fluorescence phenomenon or Raman scattering effect. Narrowband lights are frequently used as excitation sources. A popular excitation light source is the laser which generates powerful monochromatic rays. Not least, UV fluorescent lamp, narrowband LED, high-pressure arc lamp (xeon arc lamp) and low-pressure vapor lamp (mercury vapor lamp) add to the family of excitation light sources [30,31].

The core component of the spectral imaging system is the wavelength dispersive device. A wavelength dispersive device disperses broadband light into different wavelengths to be projected to the area detector. Examples of wavelength dispersive devices include the imaging spectrograph, electronically tunable filter and beam splitting device [35,36].

Compared to traditional spectrograph, an imaging spectrograph extracts both spatial and spectral information. The imaging spectrograph disperses the broadband light illuminated onto different spatial areas of a sample into different wavelengths. This is achieved through diffraction gratings. The two most popular imaging spectrographs are the prism-grating-prism (PGP) imaging spectrograph which uses transmission diffraction gratings and the Offner imaging spectrograph that uses reflection diffraction gratings $[35,36]$. These variations of imaging spectrographs are commonly applied in line scan acquisitions [37].

An electronically tunable filter utilizes electronic devices to extract the required wavelength. Current electronically tunable filters can be categorized into the acousto-optic tunable filter (AOTF) and liquid crystal tunable filter (LCTF). An AOTF utilizes an acoustic transducer to generate high frequency acoustic waves that change the refractive index of a crystal. The crystal with varied refractive index will only allow the passage of light rays at the specified wavelength. Meanwhile, a LCTF transmits light at the required wavelength through electronically controlled liquid crystal cells $[35,36]$. These electronically tunable filters allow fast and flexible wavelength switching compared to mechanical filter wheels. They too exhibit advantages of high optical throughput, narrow bandwidth and broad spectral range [38].

Unlike the electronically tunable filter, a beam splitting device allows spectral images to be obtained simultaneously at multiple wavelengths. The beam splitting device divides light into several parts and passes them through bandpass filters which correspond to the required wavelengths. The beam splitting device can be categorized into color splitting and neutral splitting. In color splitting, light rays at a particular waveband are directed to each output, whereas, in neutral splitting, an equal portion of the total light energy is directed to each output [35]. The multiple wavelength acquisition characteristic makes the beam splitting device suitable to be installed in multispectral imaging systems [39].

A spectral imaging system will not be complete without an area detector. The area detector is responsible for collecting light rays which will eventually form the spectral images of the inspected sample. The common categories of area detector are the charge-couple device (CCD) camera and the complementary metal-oxide-semiconductor (CMOS) camera [35,36].

A CCD camera is made up of millions of photodiodes (pixels) that are closely arranged to form an array. These light sensitive photodiodes convert the incident photons into electric charges that correspond to the intensity of the exposed incident rays. The accumulated electric charges at each photodiode will then be moved out of the array to be quantified for spectral image formation $[35,36]$. One of the common CCD cameras is the silicon CCD camera. The silicon CCD camera exploits the sensitivity of silicon under visible light to perform image acquisition in visible and short-wavelength near-infrared bands [40]. Indium gallium arsenide (InGaAs) CCD camera is another CCD camera variation constructed from InGaAs, an alloy between indium arsenide (InAs) and gallium arsenide (GaAs) which is sensitive in the near-infrared band [41]. Not least, mercury cadmium telluride (MCT 
or $\mathrm{HgCdTe}$ ) CCD camera built from $\mathrm{HgCdTe}$, an alloy between mercury telluride ( $\mathrm{HgTe}$ ) and cadmium telluride $(\mathrm{CdTe})$, enables sensing in the long-wavelength near-infrared and mid-infrared band [42].

Comparatively, the CMOS camera is similar to the CCD camera by having a collection of photodiodes (pixels) that convert light rays into electrical charges. The difference, however, lies in the quantification process of the electric charges. Opposed to the remote quantification in the CCD camera, the CMOS camera allows electric charges at each pixel to be independently and instantaneously read by the transistor attached to each photodiode [43]. This unique characteristic allows the CMOS camera to compete with the CCD camera in terms of high imaging acquisition speed, blooming immunity, low cost, low power consumption and small size. However, careful note should be taken as the CMOS camera is susceptible to noise due to on-chip signal transmissions, resulting in lower sensitivity and dynamic range when pitted against CCD camera [36].

\subsubsection{Spectral Imaging Processing and Analysis}

The raw spectral image data obtained via the spectral imaging technique comes in different formats according to the image acquisition method used. The common formats are Band interleaved by pixel (BIP), band interleaved by line (BIL) and band sequential (BSQ). The BIP format results from the point scan method and stores the complete spectrum of each pixel sequentially. The BIL format comes with the line scan method and stores the complete spectrum of each line in order. Lastly, the BSQ format relates to the area scan method and stacks the spatial image continuously obtained at each wavelength $[35,36]$.

Similar to the imaging and spectroscopy techniques, the raw spectral image data in BIP, BIL and BSQ formats should undergo pre-processing in both the spatial and spectral aspects before being utilized for further analysis. The raw spectral image, which represents detector signal intensity, will first undergo flat-field calibration or reflectance calibration to form useful reflectance or absorbance image. From the spatial aspect, the generated reflectance image can be further improved through image enhancement processes such as edge and contrast enhancement, magnifying, pseudo-coloring and sharpening. Noise reduction can also be achieved through spatial filtering, Fourier transform (FT) and wavelet transform (WT). From the spectral aspect, noise reduction and baseline correction can be performed through algorithms such as MSC, SNV, Savitzky-Golay smoothing, first and second derivatives, FT, WT as well as orthogonal signal correction (OSC) $[35,36]$.

The next step in the analysis flow will be image segmentation. Image segmentation serves to divide the pre-processed spectral image into different regions for the identification of region of interests (ROIs) [44]. In this process, segmentation algorithms are greatly preferred over manual segmentation due to the ease of operation and time saving. The selections of segmentation algorithms include thresholding (global thresholding or adaptive thresholding), morphological processing (erosion, dilation, open, close or watershed algorithm), edge-based segmentation (gradient-based or Laplacian-based methods) and spectral image segmentation [36].

Spatial analysis utilizing spectral image data usually involves quantitative measurement. In this process, gray-level object measurement is performed to quantify the intensity distribution of ROI extracted from image segmentation. Gray-level object measurements can be categorized according to intensity-based or texture-based measurements [45]. Intensity-based measurements are usually first-order measures such as mean [46,47], standard deviation, skew, energy and entropy [36]. Meanwhile, texture-based measurements are second-order measures such as joint distribution functions [36], gray-level co-occurrence matrix (GLCM) [46,48] and 2-D Gabor filter [49].

For spectral analysis, the data set will undergo multivariate analysis to reduce the spectral dimension and select the optimum wavelengths. Similar to the spectroscopy technique, some examples of multivariate analysis algorithms include PLS, linear discrimination analysis (LDA) [35,36], correlation analysis (CA) [50], PCA, ICA [41,51,52], ANN [53], sequential forward selection (SFS) [54] and GA [55]. These results from multivariate analysis will be used to develop calibration models for calibration, validation and prediction purposes [36]. 
The robustness of the final calibration model is evaluated from its ability to perform calibration and prediction. The calibration performance of the model is determined from the standard error of calibration (SEC), root mean square error of calibration (RMSEC) and the coefficient of determination $\left(\mathrm{r}_{\mathrm{C}}^{2}\right)$ in the calibration set. Validation performance is determined via the root mean square error of cross-validation (RMSECV) and the coefficient of determination $\left(\mathrm{r}_{\mathrm{V}}^{2}\right)$ in the validation set. Meanwhile, the prediction performance of the model is identified from standard error of prediction (SEP), root mean square error of prediction (RMSEP), residual predictive deviation (RPD) and the coefficient of determination $\left(\mathrm{r}_{\mathrm{P}}^{2}\right)$ in the prediction set. Ideally, an effective model should register low SEC, RMSEC, RMSECV, SEP and RMSEP, with a minimum difference between SEC and SEP. Not least, higher $\mathrm{r}_{\mathrm{C}^{\prime}}^{2} \mathrm{r}_{\mathrm{P}^{\prime}}^{2}$ $\mathrm{r}_{\mathrm{P}}^{2}$ and RPD are preferable [36].

\subsubsection{Pros and Cons of Spectral Imaging}

This technique is advantageous as it omits chemical processes and requires minimum sample preparation. Moreover, the composition of multiple components in a sample can be simultaneously obtained. Upon spectral image acquisition, spectral imaging too allows the flexible selection of region of interest (ROI) for analysis. Furthermore, owing to the rich spatial and spectral information, spectral imaging can easily detect and differentiate subjects even though similar colors, overlapping spectra and morphological characteristics are present [36].

However, the spectral imaging technique does pose several limitations. Hardware speed is a major concern, especially in the case of hyperspectral imaging, due to the massive amounts of data to be acquired and analyzed. Moreover, spectral imaging includes the acquisition of redundant data, resulting in complex data analysis. Spectral imaging systems too require constant calibration in order to maintain their efficiency. The detection limits of spectral imaging are poorer compared to chemical-based analytical methods. Similar to spectroscopy, spectral imaging suffers from multicollinearity and requires multivariate analysis to address the issue. In addition, spectral imaging is inapplicable when the ROI is smaller than the size of a pixel or does not exhibit the characteristic spectral absorption. Lastly, spectral imaging may be irrelevant in the analysis of liquids and homogeneous samples since these samples do not pose distinctive and useful spatial information [36].

\subsection{Technique Comparison}

Table 4 presents a simple comparison of the optics and photonics techniques in agriculture that have been discussed earlier. From the comparison, the imaging technique is noted to be utilized for the extraction of spatial information only and is sensitive to small-sized objects. In contrast to the imaging technique, the spectroscopy technique allows acquisition of spectral information and is useful in accessing multi-constituent information. The spectral imaging technique covers the benefits of both imaging and spectroscopy techniques, allowing it to obtain spectral and spatial information simultaneously. Apart from this, spectral imaging has the added value of flexible spectral extraction as well as the capability of generating quality-attribute distribution. However, it should be noted that multispectral imaging has poorer access to spectral information compared to hyperspectral imaging due to the acquisition at limited number of wavelengths. Among the compared techniques, the spectral imaging technique can be said to be the most robust. Nonetheless, the area of application should be given the utmost consideration when selecting the best optics and photonic technique in order to avoid the underutilization or overutilization of a particular technique [36]. 
Table 4. Comparison of optics and photonics techniques in agriculture [36].

\begin{tabular}{cccc}
\hline Characteristics & Imaging & Spectroscopy & Spectral Imaging \\
\hline Spectral information & $\times$ & $\checkmark$ & $\checkmark$ \\
\hline Spatial information & $\checkmark$ & $\times$ & $\checkmark$ \\
\hline Multi-constituent information & $\times$ & $\checkmark$ & $\checkmark$ \\
\hline Sensitivity to small-sized objects & $\checkmark$ & $\times$ & $\checkmark$ \\
\hline Flexibility of spectral extraction & $\times$ & $\times$ & $\checkmark$ \\
\hline Generation of quality-attribute distribution & $\times$ & $\times$ &
\end{tabular}

\section{Optics and Photonics Applications in Agriculture}

The optics and photonics techniques discussed above have been applied in various studies involving agricultural products. The studies will be tabulated in the following sections, enlisting details such as agriculture class, agriculture product, application area, wavelength details and country of applications.

\subsection{Applications of Imaging Technique}

Table 5 lists some of the agricultural works based on the imaging technique. The imaging technique is performed in the UV-VIS-IR range and involves the acquisition of spatial, color and thermal data from the inspected samples. These works show that the imaging technique is suited for inspection or analysis based on external features of the subject of interest. For instance, bruise detection $[56,57]$ and disease detection $[58,59]$ are performed by inspecting the external damage on the sample. In addition, quantitative analysis $[60,61]$ is performed using the spatial information obtained. The color features extracted are also used for maturity evaluation $[57,62,63]$ and nutrient content detection $[64,65]$. The thermal data, meanwhile, proves to be useful in similar occasions of bruise detection [66,67], disease detection [68,69] and maturity evaluation $[70,71]$ by analyzing the temperature variations over the inspected sample. Not least, the most significant application of the imaging technique is the development of automated agricultural robots [72-75] and animal behavioral studies [76,77].

Table 5. Applications of imaging technique in agriculture.

\begin{tabular}{cccc}
\hline Class & Product & Application & Ref. \\
\hline Fruit & Apple & Bruise detection (thermal) & {$[66,67,70,78]$} \\
\hline Apple & Maturity evaluation (thermal) & {$[70]$} \\
\hline Apple & Yield estimation (thermal) & {$[79]$} \\
\hline Apple & Scab disease detection (thermal) & {$[68]$} \\
\hline Green apple & Acquisition of segmented fruit region & {$[80]$} \\
\hline Green apple and orange & Yield estimation & {$[61]$} \\
\hline Orange & Texture analysis & {$[81]$} \\
\hline Orange & Bruise detection (thermal) & {$[67]$} \\
\hline Citrus & Water stress evaluation (thermal) & {$[82]$} \\
\hline Pear & Maturity evaluation (thermal) & {$[71]$} \\
\hline Banana & Maturity evaluation & {$[62]$} \\
\hline Banana & Maturity evaluation & {$[63]$} \\
\hline Persimmon & Maturity evaluation (thermal) & {$[71]$} \\
\hline Passion fruit & Mass and volume estimation & {$[83]$} \\
\hline Blueberry & Bruise detection & {$[56]$} \\
\hline Grapevine & Pathogen detection (thermal) & {$[84]$} \\
\hline Tomato & Fruit detection & {$[85,86]$} \\
\hline
\end{tabular}


Table 5. Cont

\begin{tabular}{|c|c|c|c|}
\hline Class & Product & Application & Ref. \\
\hline & Tomato & Bruise detection and maturity evaluation & [57] \\
\hline & Tomato & Bruise detection (thermal) & [87] \\
\hline & Tomato & Maturity evaluation (thermal) & [71] \\
\hline & Tomato & Clustered fruit detection & [88] \\
\hline & Sweet peppers & Peduncle detection & [89] \\
\hline & Onion & Post-harvest quality assessment (thermal) & [90] \\
\hline & Lettuce & Segmentation of vegetable & [91] \\
\hline & Cucumber & Downy mildew disease detection (thermal) & {$[69,92,93]$} \\
\hline \multirow[t]{9}{*}{ Grain } & Rice leaf & Nitrogen content detection & [64] \\
\hline & Wheat & Yield estimation (thermal) & [94-96] \\
\hline & Corn & Water stress evaluation (thermal) & [97] \\
\hline & Macadamia nuts & Yield estimation & [60] \\
\hline & Soybean & Identification of foliar disease & [98] \\
\hline & Soybean & Identification of leaf disease & [59] \\
\hline & Maize & Yield estimation (thermal) & [99] \\
\hline & Maize & Identification of leaf disease & [100] \\
\hline & Maize & Cultivar identification & [101] \\
\hline \multirow[t]{2}{*}{ Commercial } & Cotton & Water stress evaluation (thermal) & {$[97,102]$} \\
\hline & Silkworm & Gender identification & [103] \\
\hline \multirow[t]{12}{*}{ Farm and Plantation } & Seed & Viability evaluation (thermal) & [104] \\
\hline & Wheat field & Estimation of nutrient content & [65] \\
\hline & Cauliflower plantation & Weed detection & [73] \\
\hline & Asparagus plantation & Crop harvest robot vision & [74] \\
\hline & Sugar beet and rape plantation & Agriculture robot vision & [75] \\
\hline & Grapevines & Estimation of intra-parcel grape quantities & [105] \\
\hline & Cow farm & Behavioural studies & {$[76,106]$} \\
\hline & Goat and sheep farm & Animal species identification & [107] \\
\hline & Fish aquarium & Behavioural studies & {$[77,108]$} \\
\hline & Baby shrimp farm & Chlorine level detection & [109] \\
\hline & Orchid farm & Disease and pest detection & [58] \\
\hline & Surface and ground water & Chemical content detection & [110] \\
\hline
\end{tabular}

Based on Table 5, bruise detection, yield estimation, and disease identification are the three most common applications with imaging technique in agriculture. In bruise detection, a hyperspectral camera with broad operating wavelength from 400 to $5000 \mathrm{~nm}$ [78], a non-destructive and non-contact infrared sensing thermogram [66], and an infrared thermal imaging camera with high temperature resolution of $0.1 \mathrm{~K}[70]$ are among the instruments employed as the imaging technique. Moreover, the thermal camera with temperature resolution better than $0.5^{\circ} \mathrm{C}[79]$, colour stereo vision camera which creates a 3D environment for further processing [86], and grading machine with a high accuracy of $96.47 \%$ [57] are employed for yield estimation. However, the grading machine proposed in [57] has a small capacity in estimation for 300 tomatoes per hour and does not efficiently work for tomato images with high specular reflection. In addition, infrared thermography is a popular device for disease identification due to its non-invasive monitoring and indirect visualization of downy mildew development [69]. This device takes the colour reflectance image for the detection of $V$. inaequalis development on apple leaves [68] and detects the pathogen in grapevines [84]. Additionally, an X-ray computed tomography scanner is utilized to obtain the cross-section of onion inoculated by pathogens [90], whilst an unmanned aerial vehicle (UAV) is presented to track the foliar disease in soybean [98]. 
Apart from the instrument, numerous types of algorithms are depicted in imaging technique. In bruise detection, PCA and a minimum noise fraction are proposed for 20 apple samples with threshold percentages of success within $86 \%$ to $93 \%$ and $87 \%$ to $97 \%$, respectively [78]. In yield estimation, the fruit detection algorithm is presented for 8-120 apple samples with a correlation coefficient ranging from 0.83 to 0.88 [79]. In addition, the blob detector neural network is demonstrated to detect the yield estimation for both oranges and apples with intersection over union of $81.3 \%$ for orange and $83.8 \%$ for apple [61]. As for disease identification, a simple linear iterative clustering algorithm is presented for 3624 foliar images with high classification rate of $98.34 \%$ for height between 1 to $2 \mathrm{~m}$ [98]. The classification rate is reduced for approximately $2 \%$ for each meter from the examined height within 1 to $16 \mathrm{~m}$. Moreover, an improved GoogLeNet and Cifar10 models are established for 500 images of maize leaf disease with 4:1 ratio for training and validation which allows the system to have a diversity of sample conditions [100]. The average identification accuracy of GoogLeNet and Cifar10 models is recorded as high as $98.9 \%$ and $98.8 \%$, respectively. Apart from bruise detection, yield estimation, and disease identification, algorithms are also shown in maturity evaluation and acquisition of crop segmentation. In maturity evaluation, both a Fuzzy model [62] and medium filter algorithm [85] are employed for 3108 images on banana samples and 100 images on tomato samples with an average identification rate of $93.11 \%$, and within $89 \%$ to $98 \%$, respectively. The Fuzzy model is useful in handling ambiguous information for the banana fruit maturity detection using red-green-blue (RGB) components. In the acquisition of crop segmentation, K-mean clustering algorithm is presented for a clustering of apple samples with target acquisition rate of $84 \%$ [80]. This algorithm is commonly used in image segmentation whereby crop segmentation can be precisely attained, even with the presence of stems and leaves in the captured images.

\subsection{Applications of Spectroscopy Technique}

The applications of spectroscopy technique in agriculture are presented in Table 6 . The spectroscopy technique is widely applied to inspect internal qualities that are externally invisible. A sizeable amount of research has performed spectroscopy in the UV-VIS-IR region to identify the internal constituents of agricultural products such as pigment compound in apple [111], moisture content in mushroom [112], protein and sugar in potato [113], and caffeine in coffee [114] among others. Within 400 to $1000 \mathrm{~nm}$, $678 \mathrm{~nm}$ is sensitive to low chlorophyll content thus the reflectance at $678 \pm 30 \mathrm{~nm}$ is suggested for the monitoring of the early stage of ripening and the pigment content change with a maximum correlation of closely 0.6 [111]. On the other hand, 590 to $700 \mathrm{~nm}$ is recommended for the maturity detection in early stage for yellow colour apple fruits with maximum correlation from 0.7 to 0.9 . In the verification of moisture content in mushroom, the spectral region from 600 to $2200 \mathrm{~nm}$ gives the lowest standard deviation of cross validation as $0.644 \%$ and maximum correlation factor of 0.951 among the investigated wavelengths from 402 to $2490 \mathrm{~nm}$ [112]. A high experimental repeatability is presented by a standard deviation of $0.677 \%$ and a maximum correlation factor of 0.947 for a separate set of mushrooms of a similar type and treatment. In the protein and sugar content identification in potato, a modified PLS regression model is applied to calculate the relationship between the spectrum and chemical properties of the calibrated samples [113]. Based on the measurement, the standard deviations for crude protein, glucose, fructose, sucrose and red sugar for the 120 potato samples are $0.2 \%, 0.073 \%$, $0.068 \%, 0.068 \%$, and $0.122 \%$, respectively. Correspondingly, the squared correlation coefficient for the above five parameters are deduced as $0.96,0.70,0.89,0.62$, and 0.82 , respectively. In a total of 665 tea leaf samples, NIRS and liquid chromatography is coupled to a diode arrayed detector to determine its content of caffeine [114]. Among 375 calibration sets and 250 validation sets for caffeine in the tea leaf samples, a standard deviation of 8.6 and 8.9 , as well as high squared correlation coefficients of 0.97 are acquired for both calibration and validation sets though regression model.

The quality and freshness of fruits [115,116], vegetables [117], and meat $[118,119]$ can be easily inspected using spectroscopy as well. For instance, two wavelengths within 600 to $904 \mathrm{~nm}$ of VIS-NIR spectrum are investigated by correlation analysis to discriminate brown core and sound pears [115]. 
Using eight brown core pears and 32 sound pears, the percentage of soluble solid content achieves a precision of $97.8 \%$ and $99 \%$ within a standard deviation of $0.5 \%$ and $1 \%$, respectively. In addition, NIR spectrum and PLS regression model are used to detect the total anthocyanins content (TAC) and total phenolic compounds (TPC) in jambu fruits [116]. With a total of 50 jambu samples scanning from 1000 to $2400 \mathrm{~nm}$, the correlation coefficients of TAC and TPC are deduced as 0.98 and 0.94 , and strong ratio to performance of deviation as 5.19 and 3.27, respectively. Besides that, a 250 to $350 \mathrm{GHz}$ radiation is found to be suitable to distinguish the defective and proper sugar beet seeds [117]. A python package scikit-learn algorithm is used to determine the threshold for these two types of seeds, with $80 \%$ detection for proper seed and $94 \%$ detection for defective seed. Therefore, the average detection rate of this algorithm is $87 \%$. In addition, meat fraud is injected into bovine meat, aiming to increase the water holding capacity. This issue is characterized with attenuated total reflectance Fourier transform infrared spectrum and the supervision of the 55 meat fraud adulterated samples through PLS square discriminant analysis [118]. The analysis records a precise detection as high as $91 \%$ of the adulterated samples. Apart from meat fraud, the freshness of mackerel fish is characterized with auto-fluorescence spectroscopy and analyzed with fluorescence excitation emission matrices (EEM) [119]. The fluorescence EEM data and real freshness values are modelled with PLS regression and an algorithm is developed for this smart system as a predictor with squared correlation coefficient of 0.89 .

Furthermore, chemical residues in harvested product [120] or even plantation soil [121-123] can be easily identified, leading to easy detection on contamination of agricultural product. Residual pesticides such as phosmet and thiabendazole in apples are analyzed with surface-enhanced Raman spectroscopy (SERS) coupled with gold nanoparticle [120]. The sensitivities for detectable concentration are $0.5 \mu \mathrm{g} / \mathrm{g}$ for phosmet and $0.1 \mu \mathrm{g} / \mathrm{g}$ for thiabendazole. The PLS regression is also used to correlate the SERS spectrum with the concentration of pesticide in apples with squared correlation coefficient of 0936 for phosmet and 0.959 for thiabendazole. In addition, the effect of drying temperature on the nitrogen detection in soils at four different temperatures of $25{ }^{\circ} \mathrm{C}$ for placement, 50,80 , and $95{ }^{\circ} \mathrm{C}$ for drying is modelled based on NIR sensor and three successive algorithms, which are multiple linear regression, PLS, and competitive adaptive reweighed square on the spectral information [122]. Based on the three soil samples, loess, calcium soil, and black soil show the correlation coefficients of $0.9721,0.9588$, and 0.9486 , respectively at the optimum drying temperature of $80^{\circ} \mathrm{C}$. The detection of nitrogen in three types of soils is also alternatively performed in [123], with squared correlation coefficients of $0.95,0.96$ and 0.79 for loess, calcium soil and black soil using PLS regression model. The relatively lower squared correlation coefficient in black soil is due to the interference of high humus content and strong absorption of organic matter in black soil. Lastly, a point worth noting is that the dielectric and NMR spectroscopy are often adopted when the analysis involves more complex chemical compounds [124,125]. These complex chemical compounds include the vulcanization of natural rubber with sulfur-cured and peroxide-cured systems with different dynamics [124] and detection to changes in concentrations of pollutants in agriculture drainage such as heavy metal and heavy oxides [125]. In [124] a sulphur-cured system has features restricted segmented dynamics whereas peroxide-cured system has faster dynamics. In addition, network structure resulting from the vulcanization of both systems also influences the segmental dynamics of natural rubber. The peroxide-cured network is more homogeneous with spatial distribution of cross links than the sulphur-cured network with large inhomogeneity due to the presence of zinc oxide particles and the ionic interaction with the natural rubber chains. In [125], an X-ray fluorescence spectroscopy is employed to investigate the changes of pollutants in dried root and shoot plant parts at a temperature range from 30 to $90{ }^{\circ} \mathrm{C}$. From the measurement, the concentration of pollutant is found to be higher in plant root than plant shoot through the analysis of frequency relaxation process via dielectric modulus measurement. Significantly, the removal of pollutants by plants will be enhanced upon subjecting them to a microwave heating power of $400 \mathrm{~W}$ for $30 \mathrm{~min}$. Apart from the aforementioned applications, more applications of the 
spectroscopy technique in agricultural products with different methods and wavelengths are tabulated in Table 6.

Table 6. Applications of spectroscopy technique in agriculture.

\begin{tabular}{|c|c|c|c|c|c|}
\hline Class & Product & Application & Method & Wavelength (nm) & Ref. \\
\hline \multirow[t]{8}{*}{ Fruit } & Apple & $\begin{array}{l}\text { Pigment content change during } \\
\text { ripening }\end{array}$ & UV-VIS-NIR & $400-1000$ & {$[111]$} \\
\hline & Apple & Soluble solid content detection & VIS-NIR & $\begin{array}{r}500-1100 \\
1000-2500\end{array}$ & [33] \\
\hline & Apple & Pesticide residue detection & Raman & $5-18 \mu \mathrm{m}$ & {$[120]$} \\
\hline & Pear & $\begin{array}{l}\text { Brown core and soluble solid } \\
\text { content detection }\end{array}$ & UV-VIS-NIR & $200-1100$ & [115] \\
\hline & Mango & Maturity evaluation & NIR & $1200-2200$ & {$[126]$} \\
\hline & Peach & Peach variety identification & NIR & $833-2500$ & {$[127]$} \\
\hline & Wax jambu & Quality inspection & NIR & $1000-2400$ & {$[116]$} \\
\hline & Grape leaf & Water content estimation & UV-VIS-NIR & $350-2500$ & [128] \\
\hline \multirow[t]{7}{*}{ Vegetable } & Carrot & $\begin{array}{c}\text { Carotenoid, fructose, glucose, } \\
\text { sucrose and sugar content } \\
\text { detection }\end{array}$ & NIR & $1108-2490$ & [129] \\
\hline & Potato & Bruise detection & UV-VIS-NIR & $250-1750$ & {$[130]$} \\
\hline & Potato & $\begin{array}{l}\text { Protein, fructose, glucose, starch } \\
\text { and sucrose content detection }\end{array}$ & NIR & $1100-2500$ & {$[113]$} \\
\hline & Onion & Soluble solid content detection & VIS-NIR & $500-1200$ & {$[131]$} \\
\hline & $\begin{array}{l}\text { Oilseed rape } \\
\text { leaf }\end{array}$ & Aspartic acid content detection & NIR & $1100-2500$ & {$[132]$} \\
\hline & $\begin{array}{l}\text { Sugar beet } \\
\text { seeds }\end{array}$ & Quality control & $\begin{array}{l}\text { Time-domain } \\
\text { spectroscopy }\end{array}$ & $250-350 \mathrm{GHz}$ & [117] \\
\hline & Mushroom & Moisture content detection & VIS-NIR & $600-2200$ & {$[112]$} \\
\hline \multirow[t]{4}{*}{ Grain } & Corn seed & Viability evaluation & $\begin{array}{c}\text { NIR } \\
\text { Raman }\end{array}$ & $\begin{array}{c}1000-2500 \\
3.125-59 \mu \mathrm{m}\end{array}$ & {$[133]$} \\
\hline & Almond & Internal defect detection & VIS-NIR & $700-1400$ & $\begin{array}{l}{[134,} \\
135]\end{array}$ \\
\hline & Maize & $\begin{array}{l}\text { Identification of transgenic } \\
\text { ingredients }\end{array}$ & THz spectral & $0-4.5 \mathrm{THz}$ & [136] \\
\hline & $\begin{array}{l}\text { Rice, maize and } \\
\text { peanut }\end{array}$ & Germination and growth of crop & $\begin{array}{l}\text { UV-VIS } \\
\text { FTIR }\end{array}$ & $\begin{array}{c}380.85-796.62 \mathrm{~nm} \\
562.72-3865.11 \mathrm{~cm}^{-1}\end{array}$ & [137] \\
\hline \multirow[t]{3}{*}{ Meat } & Beef & Thermal change inspection & Fluorescence & $250-550$ & {$[138]$} \\
\hline & Beef & Adulteration detection & NIR-MIR & $2.5-19 \mu \mathrm{m}$ & [118] \\
\hline & Frozen fish & Freshness evaluation & Fluorescence & $250-800$ & [119] \\
\hline \multirow[t]{2}{*}{ Dairy } & Egg & Contamination detection & UV-VIS-NIR & $200-860$ & {$[139]$} \\
\hline & Goat milk & Fatty acid content detection & VIS-NIR & $400-2498$ & {$[140]$} \\
\hline \multirow[t]{3}{*}{ Oil } & Edible oil & Stability analysis & NMR & $300 \mathrm{MHz}(1 \mathrm{H})$ & {$[141]$} \\
\hline & Olive oil & Adulteration detection & Fluorescence & $250-720$ & {$[142]$} \\
\hline & $\begin{array}{c}\text { Ocimum } \\
\text { essential oil }\end{array}$ & $\begin{array}{l}\text { Antioxidant property } \\
\text { identification }\end{array}$ & NIR-MIR & $2.5-18 \mu \mathrm{m}$ & {$[143]$} \\
\hline \multirow[t]{7}{*}{ Beverage } & Tea leaf & Tea polyphenol level detection & UV-VIS-NIR & $347-2506$ & {$[144]$} \\
\hline & Green tea leaf & $\begin{array}{l}\text { Caffeine and catechins content } \\
\text { detection }\end{array}$ & VIS-NIR & $400-2500$ & {$[114]$} \\
\hline & Coffee & $\begin{array}{l}\text { Geographic and genotypic origin } \\
\text { identification }\end{array}$ & NIR & $1100-2498$ & [145] \\
\hline & Coffee & $\begin{array}{l}\text { Roasting degree and blend } \\
\text { composition detection }\end{array}$ & NIR & $800-2857$ & [146] \\
\hline & Tomato juice & Quality inspection & NIR-MIR & $2.5-14 \mu \mathrm{m}$ & {$[147]$} \\
\hline & Apple wine & Volatile compound detection & NIR & $833-2500$ & {$[148]$} \\
\hline & Rice wine & Fermentation monitoring & NIR-MIR & $2.5-25 \mu \mathrm{m}$ & {$[149]$} \\
\hline
\end{tabular}


Table 6. Cont

\begin{tabular}{|c|c|c|c|c|c|}
\hline Class & Product & Application & Method & Wavelength (nm) & Ref. \\
\hline \multirow[t]{8}{*}{ Commercial } & Cotton fibre & Cotton type identification & NIR & $800-2500$ & [150] \\
\hline & Cotton fibre & $\begin{array}{l}\text { Cotton fibre micronaire } \\
\text { measurement }\end{array}$ & VIS-NIR & $400-2500$ & [151] \\
\hline & Natural rubber & $\begin{array}{c}\text { Protein and lipid content } \\
\text { detection }\end{array}$ & NIR-MIR & $2.5-25 \mu \mathrm{m}$ & [152] \\
\hline & Natural rubber & $\begin{array}{l}\text { Chemical interaction during } \\
\text { vulcanizing process }\end{array}$ & $\begin{array}{l}\text { NIR-MIR } \\
\text { Raman }\end{array}$ & $\begin{array}{c}2.5-25 \mu \mathrm{m} \\
3.125-100 \mu \mathrm{m}, \\
6.25-50 \mu \mathrm{m}\end{array}$ & [153] \\
\hline & Natural rubber & Rubber silane reaction & NMR & $\begin{array}{l}400 \mathrm{MHz}(1 \mathrm{H}) \\
100.6 \mathrm{MHz}(13 \mathrm{C})\end{array}$ & [154] \\
\hline & Natural rubber & Moisture content detection & VIS-NIR & $400-1100$ & [155] \\
\hline & Natural rubber & Vulcanization system effect & $\begin{array}{l}\text { Dielectric } \\
\text { NMR }\end{array}$ & $\begin{array}{c}10-1<\mathrm{Hz}<107 \\
20 \mathrm{MHz}(1 \mathrm{H})\end{array}$ & [124] \\
\hline & Neem leaf & Pest control & $\begin{array}{l}\text { UV-VIS } \\
\text { FTIR } \\
\text { XRD }\end{array}$ & $\begin{array}{c}200-800 \mathrm{~nm} \\
250-4000 \mathrm{~cm}^{-1} \\
10-80^{\circ}\end{array}$ & [156] \\
\hline \multirow{8}{*}{$\begin{array}{l}\text { Farm and } \\
\text { Plantation }\end{array}$} & Soil & Quality inspection & NIR & $780-5000$ & [157] \\
\hline & Soil & Nitrogen content detection & NIR & $800-2564$ & [158] \\
\hline & Soil & $\begin{array}{l}\text { Chemical and physical property } \\
\text { estimation }\end{array}$ & NIR-MIR & $\begin{array}{l}1430-2500 \\
2.5-27 \mu \mathrm{m}\end{array}$ & [159] \\
\hline & Soil & Nitrogen detection & NIR & $900-1700$ & [122] \\
\hline & Soil & Nitrogen detection & NIR & $900-1700$ & [123] \\
\hline & Soil and water & Contaminant detection & VIS-NIR & $400-2500$ & [121] \\
\hline & $\begin{array}{l}\text { Water hyacinth } \\
\text { Soybean straw }\end{array}$ & $\begin{array}{l}\text { Pollutant concentration detection } \\
\text { Detection of biomass }\end{array}$ & $\begin{array}{c}\text { Dielectric } \\
\text { Fluorescence } \\
\text { Near infrared } \\
\text { spectroscopy }\end{array}$ & $\begin{array}{c}10-1<\mathrm{Hz}<106 \\
\mathrm{~N} / \mathrm{A} \\
4000-12,000 \mathrm{~cm}^{-1}\end{array}$ & $\begin{array}{l}{[125]} \\
{[160]}\end{array}$ \\
\hline & Flower & Plant type identification & VIS & $635,685,785$ & [161] \\
\hline
\end{tabular}

\subsection{Applications of Spectral Imaging Technique}

As discussed earlier, the spectral imaging technique is a combination of both imaging and spectroscopy techniques. In the agriculture industry, both variations of hyperspectral and multispectral imaging are equally crucial, and some sample applications are compiled in Table 7. As observed from Table 7, hyperspectral imaging involves acquisition over a range of wavelengths while multispectral imaging involved acquisition at fewer selected wavelengths. The robustness of spectral imaging allows its usage in bruise detection [78,162,163], maturity evaluation [164-168], quality evaluation [169-171] and disease detection [172-176]. Internal attributes of samples [177-179] are easily acquired for analysis purposes as well.

In bruise detection of agriculture product, a machine vision system is integrated with optical filter at 740 and $950 \mathrm{~nm}$ to detect the bruise in rotating apple with a detection accuracy of 90 to $92 \%$ from 54 Pink Lady apples and 60 Ginger Gold apples [162]. In addition, the bruise detection in mushroom is carried out through a line scanning hyperspectral imaging instrument from 400 to $1000 \mathrm{~nm}$ with a spectroscopic resolution of $5 \mathrm{~nm}$ [163]. The PCA is applied to a set of data comprising of 50 normal and 50 bruise spectra, with standard deviation of 0.025 and 0.055 , respectively.

For the maturity evaluation of agriculture products such as peach fruit, a CCD camera is employed at 450, 675 and $800 \mathrm{~nm}$, whereas the fruit ripening is characterized with the increasing in intensity from a histogram with a ratio of red divide with infrared red (R/IR) [164]. The firmness of the peach fruit reduces when the reflectance at $675 \mathrm{~nm}$ is increased. An analysis of variance (ANOVA) is presented to access the R/IR clustering which has the highest reflectance at $675 \mathrm{~nm}$, and higher Fisher value as a function of higher R/IR ratio. Apart from the detection of maturity for peach fruit, the maturity stage of strawberry is detected using a hyperspectral imaging system from 380 to $1030 \mathrm{~nm}$ and from 874 to 
$1734 \mathrm{~nm}$ [165]. According to the PCA, the optimal wavelengths are from 441.1 to $1013.97 \mathrm{~nm}$ and from 941.46 to $1578.13 \mathrm{~nm}$ with a classification accuracy of above $85 \%$. Moreover, the maturity of tomato is detected by an electromagnetic spectrum with a continuous 257 bands from 396 to $736 \mathrm{~nm}$ [166] and discrete band of 530,595, 630, and $850 \mathrm{~nm}$ using a tomato maturity predictive sensor [167]. Based on the LDA, the classification error is reduced from 51\% to 19\% [166] and achieves detection accuracy above 85\% [167]. The ripening in banana fruit is also characterized with a compact imaging system and an UAV from 500 to $700 \mathrm{~nm}$ [168]. The detection is based on the reflectance spectrum whereby in ripe banana, the main element is carotenoid which absorbs less light at $650 \mathrm{~nm}$ band. On the other hand, a green banana with a greater amount of chlorophyll than ripe banana absorbs more light at $650 \mathrm{~nm}$ band.

For the quality evaluation of agriculture product, the firmness test for two types of apple fruits is conducted with a laser-based multispectral imaging prototype which captures and processes four spectral scattering images at a speed of two fruits per second [169]. The multilinear regression models are developed using to predict the firmness of those two apple types at 680, 880, 905, and $940 \mathrm{~nm}$ with a correlation coefficient of 0.86 . The quality of grape berries is determined by the reflectance spectrum from a hyperspectral imaging system, whilst the high reflectance at $500 \mathrm{~nm}, 660$ to $700 \mathrm{~nm}$, and $840 \mathrm{~nm}$ denotes the chlorophyll content, red-coloured anthocyanin pigment, and sugar content, respectively [170]. A partial least square regression (PLSR) model is applied in order to determine the correlation between the spectral information and the physico-chemical indices. The titratable acidity of the green and black grapes shows a coefficient of determination of 0.95 and 0.82 , as well as soluble solid content of 0.94 and 0.93 at $\mathrm{pH}$ value of 0.8 and 0.9 , respectively. The root mean square error for this method is 0.06 for green grape and 0.25 for black grape. Apart from fruits, the quality of tea leaves is classified by a hyperspectral imaging sensor at 762,793, and $838 \mathrm{~nm}$, supported by SVM algorithm [171]. Within 700 samples comprising of 500 training samples and 200 prediction sets, the SVM algorithm generates a total classification rate of $98 \%$ the training sample and $95 \%$ for the prediction set, at result of optimal regularization parameter of 4.37349 and kernel parameter of 13.2131 in SVM model.

For the disease detection in agriculture product, a fruit sorting machine is used to detect the citrus canker at 730 and $830 \mathrm{~nm}$ with a bandpass filter installed in the scanning camera [172]. A real-time image processing and classification algorithm is developed based on a two-band ratio (R830/R730) approach, which achieves a detection accuracy of $95.3 \%$ for 360 citrus samples. Next, a shortwave infrared hyperspectral imaging system is used to detect the sour skin in onion based on the suitable reflectance spectrum from 1070 to $1400 \mathrm{~nm}$ [173]. Two image analysis approaches are utilized based on the log-ratio images at two optimal wavelengths of 1070 and $1400 \mathrm{~nm}$. A global threshold of 0.45 is integrated to segregate sour onion skin infection areas from log-ratio images. With Fisher's discriminant analysis, the detection accuracy of $80 \%$ is achieved. The second image analysis approach is the incorporation of three parameters; max, contrast and homogeneity of the log-ratio images as the input features for the SVM. Subsequently, the Gaussian kernel generates higher detection accuracy as $87.14 \%$. Apart from that, the tumorous chicken is detected by the combination of a CCD camera and imaging spectrograph from 420 to $850 \mathrm{~nm}$ [174]. Within the wavelength bands, the PCA select the three useful wavelengths of 465,575, and $705 \mathrm{~nm}$ from the tumorous chicken image. Based on the images from 60 tumorous and 20 normal chicken, multispectral image analysis generates the ratio images, which are divided into ROI classified either as tumorous or normal chicken. The image features from ROI such as coefficient of variation, skewness and kurtosis are extracted as the input for the Fuzzy classifier, which generates the detection accuracy of $91 \%$ for normal chicken and $86 \%$ for tumorous chicken. To detect the nematodes in coffee cultivation, hyperspectral data is used in band simulation of the RapidEye sensor to determine the most sensitive spectral ranges for pathogen discrimination in coffee plants [176]. Multispectral classification identifies the spatial distribution of healthy, moderately infected, and severely infected coffee plants with an overall accuracy of $71 \%$. Apart from the four 
main applications with the spectral imaging technique in agriculture products, more applications with different scanning methods and various wavelengths are tabulated in Table 7.

Table 7. Applications of spectral imaging technique in agriculture.

\begin{tabular}{|c|c|c|c|c|c|}
\hline Class & Product & Application & Method & Wavelength (nm) & Ref. \\
\hline \multirow[t]{17}{*}{ Fruit } & Apple & Bruise detection & Hyper. line scan & $\begin{array}{r}400-2500 \\
1000-2500\end{array}$ & {$[78,180]$} \\
\hline & Apple & Bruise detection timing & Hyper. line scan & $400-2500$ & [181] \\
\hline & Apple & Bruise detection & Multi. area scan & 740,950 & [162] \\
\hline & Apple & Bruise and faeces detection & Multi. line scan & $530,665,750,800$ & [182] \\
\hline & Apple & Firmness evaluation & Multi. area scan & $680,880,905,940$ & [169] \\
\hline & Citrus & Canker detection & Multi. area scan & 730,830 & [172] \\
\hline & Peach & Firmness evaluation & Hyper. line scan & $500-1000$ & [183] \\
\hline & Peach & Maturity evaluation & Multi. area scan & $450,675,800$ & [164] \\
\hline & Cantaloupe & Faeces detection & Hyper. line scan & $425-774$ & [184] \\
\hline & Blueberry & $\begin{array}{l}\text { Firmness evaluation, soluble } \\
\text { solid content detection }\end{array}$ & Hyper. line scan & $400-1000$ & {$[177,185]$} \\
\hline & Strawberry & Maturity evaluation & Hyper. line scan & $\begin{array}{l}380-1030 \\
874-1734\end{array}$ & [165] \\
\hline & Cherry & Pit detection & Hyper. line scan & $450-1000$ & [186] \\
\hline & Grape & Quality evaluation & Hyper. line scan & $400-1000$ & [170] \\
\hline & Banana & Maturity evaluation & Hyper. area scan & $500-700$ & [168] \\
\hline & Tomato & Maturity evaluation & Hyper. line scan & $396-736$ & [166] \\
\hline & Tomato & Maturity evaluation & Multi. area scan & $530,595,630,850$ & [167] \\
\hline & Cucumber & Chilling injury detection & Hyper. line scan & $447-951$ & [187] \\
\hline \multirow[t]{4}{*}{ Vegetable } & $\begin{array}{l}\text { Freeze-dried } \\
\text { broccoli }\end{array}$ & Glucosinolate detection & Hyper. line scan & $400-1700$ & [188] \\
\hline & Potato & Cooking time prediction & Hyper. line scan & $400-1000$ & [189] \\
\hline & Onion & Sour skin disease detection & Hyper. area scan & $950-1650$ & [173] \\
\hline & Mushroom & Bruise detection & Hyper. line scan & $400-1000$ & [163] \\
\hline \multirow[t]{7}{*}{ Grain } & Rice plant & Nitrogen content detection & Hyper. line scan & $400-1000$ & {$[190,191]$} \\
\hline & $\begin{array}{l}\text { Thai jasmine } \\
\text { rice }\end{array}$ & Rice variety identification & Multi. area scan & 545,575 & [192] \\
\hline & Wheat & Fungus detection & Hyper. area scan & $1000-1600$ & [193] \\
\hline & Wheat & Damage detection & Hyper. line scan & $1000-2500$ & [194] \\
\hline & Peanut & $\begin{array}{c}\text { Tomato spot wilt disease } \\
\text { detection }\end{array}$ & Multi. Area scan & $475,560,668,717,840$ & [195] \\
\hline & Corn & $\begin{array}{l}\text { Oil and oleic acid content } \\
\text { detection }\end{array}$ & Hyper. area scan & $950-1700$ & [196] \\
\hline & Corn & Aflatoxin detection & Hyper. line scan & $400-600$ & [197] \\
\hline \multirow[t]{12}{*}{ Meat } & Chicken & Skin tumour detection & Hyper. line scan & $420-850$ & [174] \\
\hline & Chicken & Heart disease detection & Multi. area scan & $495,535,585,605$ & [198] \\
\hline & Chicken & Faeces detection & Multi. area scan & 520,560 & [199] \\
\hline & Chicken & Wholesomeness inspection & Multi. line scan & 580,620 & [200] \\
\hline & Beef & Tenderness evaluation & Hyper. line scan & $400-1000$ & [201] \\
\hline & Beef & Microbial spoilage detection & Hyper. line scan & $400-1100$ & [202] \\
\hline & Lamb & Lamb variety identification & Hyper. line scan & $900-1700$ & [203] \\
\hline & Pork meat & E. coli detection & Hyper. line scan & $470-960$ & [204] \\
\hline & Pork meat & Quality inspection & Hyper. line scan & $900-1700$ & [205] \\
\hline & Fish & $\begin{array}{c}\text { Moisture and fat content } \\
\text { detection }\end{array}$ & Hyper. line scan & $460-1040$ & [206] \\
\hline & Fish & Ridge detection & Hyper. line scan & $400-1000$ & [207] \\
\hline & Salmon & Microbial spoilage detection & Hyper. line scan & $\begin{array}{l}400-1000 \\
880-1720\end{array}$ & [208] \\
\hline
\end{tabular}


Table 7. Cont

\begin{tabular}{|c|c|c|c|c|c|}
\hline Class & Product & Application & Method & Wavelength (nm) & Ref. \\
\hline & $\begin{array}{l}\text { Dehydrated } \\
\text { prawn }\end{array}$ & Moisture content detection & Hyper. line scan & $380-1100$ & [209] \\
\hline & Prawn & Adulteration detection & Hyper. line scan & $\begin{array}{l}380-1030 \\
900-1700\end{array}$ & [210] \\
\hline \multirow[t]{3}{*}{ Dairy } & Milk powder & Melamine detection & Hyper. line scan & $990-1700$ & [211] \\
\hline & Milk & Fat content detection & Hyper. line scan & $530-900$ & [178] \\
\hline & Milk & Melamine detection & Hyper. point scan & $4-98 \mu \mathrm{m}$ & {$[212]$} \\
\hline Oil & Olive oil & $\begin{array}{l}\text { Free acidity, peroxide and } \\
\text { moisture content detection }\end{array}$ & Hyper. line scan & 900-1700 & [179] \\
\hline \multirow[t]{3}{*}{ Beverage } & Tea & Quality inspection & Hyper. line scan & $408-1117$ & [171] \\
\hline & Tea & Moisture content detection & Hyper. line scan & $874-1734$ & [213] \\
\hline & Tea & Tea variety identification & Multi. area scan & $580,680,800$ & [214] \\
\hline \multirow[t]{3}{*}{$\begin{array}{l}\text { Farm and } \\
\text { Plantation }\end{array}$} & Tea bush & $\begin{array}{l}\text { Tea variety, growth status and } \\
\text { disease identification }\end{array}$ & Hyper. area scan & $325-1075$ & [175] \\
\hline & Coffee crop & Detection of disease/infection & Hyper. area scan & $440-850$ & [176] \\
\hline & $\begin{array}{c}\text { Coffee } \\
\text { plantation }\end{array}$ & Monitoring chlorophyll content & Multi. area scan & $490-2190$ & [215] \\
\hline
\end{tabular}

\section{Photonics Techniques Implementation in Food Safety Inspection and Quality Control}

Food safety inspection and quality control is important for ensuring the high quality of agriculture products. To meet this criterion, photonics techniques have been extensively implemented into numerous applications. For instance, clean drinking water is undeniably one of the most important elements to sustain the organisms' life. Contamination may happen when treated drinking water is travelling in the distribution system to the consumer, whilst the sensitivity to the inhibitor of contamination can be measured by the elevated dissolved organic matter (DOM) at the tap relative to the water leaving the treatment plant [216]. Across a biologically stable drinking water system, humic-like fluorescence (HLF) intensities of less than $2.2 \%$ relative standard deviation are measured after accounting for quenching by copper. In addition, a minor infiltration of a contaminant is detectable by sewage with a strong tryptophan-like fluorescence (TLF) signal thus validating the potential of DOM fluorescence in detecting the water quality changes in drinking water system. Moreover, fluorescence spectroscopy was demonstrated in evaluating the microbial quality of untreated drinking water through online monitoring [217]. The DOM peaks are targeted at excitation and emission wavelengths of 280 and $365 \mathrm{~nm}$ for TLF, as well as 280 and $450 \mathrm{~nm}$ for HLF. Both TLF and HLF are strongly correlated to micro-bacterial cells such as $E$. coli with a correlation coefficient of 0.71 to 0.77 . In comparison to turbidity for E. coli with correlation coefficient of only 0.4 to 0.48 , the DOM sensor appears to be a better indicator for micro-bacterial cells in untreated drinking water. Apart from the DOM sensor, an optical sensor was proposed to differentiate the particles in drinking water as either bacteria or abiotic particles with an accuracy of $90 \pm 7 \%$ and $78 \pm 14 \%$ for monotype and fix-type suspensions, respectively, based on a 3D image recognition and classification algorithm [218]. In addition, this optical sensor can detect micro-particles with minimum size of $0.77 \mu \mathrm{m}$. Significantly, the aforementioned optical sensors incorporating photonic techniques serve as an early warning for drinking water pollution.

Photonics and optics have also recently gained popularity in the quality inspection of food product. This is because food inspection in the production line needs to be carried out at fast speed and a very fast monitoring system is needed. Food inspection can become even more challenging when it is dealing with large quantities of sample moving very quickly on the conveyor belt. Therefore, high speed and high sensitivity optical system will be very suitable for the online monitoring and inspection of food product. For example, research work on UV-visible-NIR optical spectroscopy have been carried out extensively in the monitoring of extra virgin olive oil [219], honey [220], tea [221], dairy product [222] and alcoholic beverages [223]. However, as these works focus on wavebands below 
$1100 \mathrm{~nm}$, the results and consistency of the conclusions may be easily affected by ambient lighting conditions and the change in color of the beverages or product. Therefore, more research work shall be carried out to characterize these food products in the NIR (>1100 nm) and MIR wavebands in order to obtain the optical "fingerprint" that correlates to the quality and food safety level of the product.

In addition, food preservative exceeding the allowable limit has been a critical issue in ensuring the health of the public. Butylated Hydroxytoluene (BHT) is commonly used as an antioxidant agent in canned food or bottled beverages. Several optical sensing techniques such as optical spectroscopy and fluorescence may be able to detect the concentration of BHT. BHT is also commonly known as 2,6-ditertiarybutyl-para-cresol (DBPC). Recently, Leong et al. [224] reported the detection of DBPC in transformer oil using optical spectroscopy at waveband near to $1403 \mathrm{~nm}$. This opens up the opportunity of detecting the concentration of BHT in canned food or bottled beverages, leading to an online monitoring system that uses the optical spectroscopy method.

Due to the lack of attention paid during the preparation processes or due to the contamination of water and environment, hazardous residual materials are occasionally found in food. These hazardous materials include heavy metal, pesticides and antibiotics. Conventionally, the screening process or food safety inspections were carried out using laboratory-based equipment or measurement methods such as gas chromatography (GC), GC-mass spectrometry and high-performance liquid chromatography [225]. However, these methods only allow inspection based on sampling due to the high cost and long result waiting time. In this context, optical detection methods such as optical spectroscopy, Raman spectroscopy and fluorescence can be explored for their possible utilization in the online monitoring of food products in order to ensure that they are free of hazardous residual materials.

\section{Photonics Techniques Implementation in Tropical Countries Agriculture}

Blessed with wide spans of fertile soil, rich marine ecology, abundant rainfall and a tropical climate, tropical countries are exceptionally suited for a myriad of agricultural activities [226-228]. Agriculture activities boost the country's economy by supplying food sources and industrial raw materials. This sector also provides income to farmers, raising their living standards in rural areas. An example of tropical countries with active agricultural activities is Malaysia. Dating back to the early years following Malaysia's independence in 1957, the agriculture sector has been a signifficant driver towards socio-economic development in Malaysia. However, in the early 1980s, the growth of the agricultural field came to an abrupt halt due to the sharp decline in commodity prices, limited technical specialty, volatile rubber prices and lack of incentives $[229,230]$. Industrialization soon became the leading economic sector, with great focus directed towards manufacturing and services [230]. Fortunately, the agriculture sector is once again emphasized upon the Asian financial crisis in 1997, acting as a measure to minimize external economic shock by first strengthening the domestic economy [227,231]. Since then, agriculture has always been a major agenda item of Malaysian economic plans, with a recent target directed towards modernizing agriculture as drafted in the Eleventh Malaysia Plan [232]. To date, amidst industrial developments, Malaysia has approximately 4.06 million hectares of agricultural land, with $80 \%$ allocated for commercial crops such as palm oil, rubber, cocoa, coconut and pepper [229,233], while a portion of the remaining $20 \%$ was utilized for the cultivation of agro-food crops [226]. These remarkable statistics have validated the potential of a tropical country to develop its agricultural sector. Apart from Malaysia, other tropical countries such as Indonesia and Thailand are also actively involved in agriculture activities. The following sections will discuss some of the agricultural crops in tropical countries in which optics and photonic techniques can be easily integrated for automated plantation management, yield increment, quality inspection and disease control.

\subsection{Implementation in Palm Oil-Related Activities}

Palm oil is an extremely valuable commercial crop in tropical countries. Palm oil, which is extracted from oil palm, is often used as raw materials for the production of biofuel, biofertilizers, 
oleochemicals, biomass products, nutraceuticals and pharmaceuticals. In fact, tropical countries are among the global leaders in the palm oil industry [234]. The implementation of optics and photonic techniques in palm oil-related activities will maintain the competitive power of the tropical countries in the field and help to reap the associated economic benefits.

The implementation of optics and photonics techniques in oil palm related activities can start from the development of agriculture robots. The development of an agriculture robot involves the implementation of the imaging technique in its operation. Spatial and color information attained by the agriculture robot through the imaging technique will greatly improve the efficiency of palm oil plantation management. Automated palm oil fruit harvest is potentially applicable by pinpointing the fruit position as presented in $[72,74,75]$ for other crops. Besides, automated weed detection and removal [73] as well as automated fertilizing can be performed using the developed agriculture robot.

In addition, palm oil quality is governed by fatty acid, moisture and peroxide contents. Microbial or oxidation reactions that take place during the storage of oil palm fruit may modify these contents, resulting in a depreciation of palm oil quality [235]. Under common operations, palm oil plantations are usually distanced further away from refinery factories. Bulk transport of palm fruit upon reaching the necessary processing quota is often practiced for cost savings. As a result, palm fruits that have been harvested earlier will be stored in dedicated storage spaces. The time difference between harvesting and processing greatly increases the risk for microbial or oxidation reaction to take place. In this scenario, spectroscopy or spectral imaging can be implemented in the palm oil extraction stage to perform oil quality segregation. This will greatly prevent contamination of low-quality palm oil in further downstream processes, promoting process efficiency and increasing palm oil yield.

Another area in which optics and photonics techniques may be applied for oil palm activities is disease detection. The most devastating diseases that attack palm oil plantations in South East Asia are basal stem rot (BSR) and upper stem rot (USR). These diseases result in certain death of oil palms if not controlled effectively, resulting in yield loss and disrupting the plantation cycle. These fatal diseases are identified to be caused by the Ganoderma boninense (G. boninense) fungus. However, the identification of the root cause of these diseases is still insufficient as they cannot be controlled even with the slightest delay in infection detection [236]. In this area, spectral imaging presents itself as one of the possible alternatives to perform early detection of the G. boninense fungus [237]. Samples of suspicious fungi in the palm oil plantation can be simultaneously collected and analyzed to identify the presence of disease-causing G. boninense. From here, preventive measures can be effectively performed to curb any possible disease spreading.

\subsection{Implementation in Natural Rubber Related Activities}

Natural rubber is an important commodity that finds it place in the manufacturing of various household, industrial and medical products. Rubber tree plantations have been widely established in the fertile soils of tropical countries. The usage of optics and photonic techniques will again prove to be beneficial in this area.

The simplest idea will again start from the usage of agriculture robots during the plantation stage. In the context of rubber tree plantations, the imaging technique will provide visual guidance for the agriculture robots to perform the scheduled collection of field latex. The usage of these robots will gradually replace manual latex collection done by rubber tappers. This approach will address the decline in manpower to maintain rubber tree plantations.

Meanwhile, the spectroscopy technique can be utilized in the later rubber processing stages. The first application would be rubber quality grading. For instance, cup lump raw rubber, which is an important material in tires, seal strips, conveyor belts and other moulded rubber products, can be graded by using VIS-NIR spectroscopy to inspect the moisture content of the rubber. This spectroscopic approach is fast, accurate and more reliable compared to manual inspection through sight and touch [155]. Similarly, the protein and lipid contents in natural rubber can be detected through NIR-MIR spectroscopy to enable grading [152]. Lastly, spectroscopy variations, such as NIR-MIR, Raman, 
dielectric or NMR, can be opted to study the structure and properties of rubber during vulcanization. Such studies allow the analysis and selection of accelerators, activators and retarders, leading to improved characteristics in the vulcanized rubber and an optimized vulcanizing process $[124,153]$.

\subsection{Implementation in Agro-Food Crops Related Activities}

It is important to increase food production and achieve a self-sufficiency level (SSL) for a growing country to become an advanced country. Currently, the agro-food crops in tropical countries comprise of grains, organic fruits and vegetables, herbs and spices, livestock and fisheries [232,234]. By referring to some of the applications stated in Sections 3.1-3.3, optics and photonic techniques can once again improve the overall quality and yield of these crops.

Starting from grains such as rice and corn, crop harvest [72] and weed removal [73] can be easily performed by agriculture robots with imaging capabilities. Thermal imaging can be conducted to evaluate water stress in crops for irrigation control [97]. Moreover, the development of mobile phone application to perform color-based identification of nitrogen content in rice and corn plant is another interesting idea. The usage of such applications promotes the portable and on-site analysis of fertilizer requirements in crop fields [64].

At the same time, all three optics and photonic techniques discussed earlier can be fully utilized to inspect the harvested organic fruits and vegetables for quality evaluation. For instance, imaging in either VIS or IR region is useful in detecting external damage or bruises in mangosteens, wax jambus, cherry tomatoes and more. Spectroscopy may be performed as well to inspect internal features or maturity of fruits and vegetables. Not least, spectral imaging may be considered when spatial and spectral information are required simultaneously for quality evaluation. Meanwhile, the quality inspection of meat products, such as chicken, beef, lamb, and fish among others, is strongly preferred to be performed using spectroscopy or spectral imaging. These two techniques are suitable for identifying the microbial spoilage of meat products due to their ability to obtain spectral information. With the integration and application of optics and photonics in the agriculture industry, it is anticipated that the agricultural products in the tropical countries will meet the public expectation of higher food quality.

\subsection{Possible Challenges}

The prevailing research challenges of integrating optics and photonics techniques into the agriculture field are the reliability issue of the laser source and sensor, effect of the ambient environmental condition into optics system, and expensive semiconductor materials at operating wavelength from short to mid-IR range. First and foremost, the illumination intensity of the laser and the sensitivity of the sensor may change over time, which leads to the need for recalibration of the system. Therefore, more research is required in terms of the design and fabrication of a more reliable laser source, sensor and optical detector. In addition, the effect of the ambient condition such as humidity, surrounding temperature, and dust particles could be a hindrance in ensuring consistent results obtained from the optical system. Hence, research into the minimization of these effects on the optical system is significant to improve the system performance such as higher sensitivity, lower systematic error and maintenance rate. Moreover, silicon is well-known for its optimum wavelength operation below $1000 \mathrm{~nm}$. From short to mid-IR range, examples of more viable semiconductor materials are gallium antimonide and indium gallium arsenide. The investigation in terms of generating a higher efficiency using these materials for a cost-effective solution creates the research opportunities for further exploration in both simulation and experimental works.

Apart from the research challenges, the main challenge in introducing the discussed optics and photonic techniques into the field of agriculture in tropical countries would be gaining the acceptance of farmers, fisherman and smallholders. The introduction of modern technology and new agriculture practices often raises concerns surrounding their technical and economic feasibilities. Farm and plantation owners will prefer traditional agriculture practices as newly introduced technologies are often regarded to be more suited to a controlled laboratory environment. In this scenario, technology 
vendors should ensure that complete field testing has been done in the environment where the technology will be introduced. A probationary period may also be set to allow owners to try out and experience the benefits brought forth by the proposed technologies.

The next challenge would be on financial limitations. In general, the cost to fully implement optics and photonics techniques in existing agriculture activities may be a burden to the owners, especially those involving sophisticated optical tools. This deterring factor may be mitigated if financial aids are provided to the owners. In this case, the government of tropical countries should set the right path by providing funds to the owners through attractive policies. For instance, a loan policy of flexible repayment based on harvest cycles is more attractive compared to one of fixed term financing since owners are now presented with flexible loans [232].

Lastly, another challenge lies with the need of technical support. When introducing the optics and photonic techniques, technical training should be provided to farm and plantation workers in order to familiarize them with the operations of new tools. At the same time, advisory and technical services should be easily available in case the agriculture tools experience downtime or require scheduled maintenance.

\section{Conclusions}

In conclusion, optics and photonics exhibit great benefits if they are integrated into the agricultural industry. A complete knowledge of the behaviors and properties of light upon light-material interaction allows the quantitative and qualitative analysis of agriculture products. In general, optics and photonic techniques for agricultural purposes can be categorized into imaging, spectroscopy and spectral imaging techniques. The imaging technique is effective in collecting spatial, color and thermal information, whereas the spectroscopy technique is essential for collecting spectral information. Meanwhile, spectral imaging is a combination of both imaging and spectroscopy techniques, allowing the collection of a complete data set. These three optics and photonic techniques have been utilized in agriculture categories such as fruits, vegetables, grain, meat, dairy produce, oil, beverages, and commercial crops, as well as farm and plantation management. These works can be referred to and emulated in the agriculture industry of tropical countries, especially in agriculture activities related to oil palm, rubber and agro-food crops. However, challenges in terms of public acceptance, finance and technical support should be overcome before achieving a complete integration of optics and photonics techniques in the agriculture industry.

Thus, the key contribution of this study is the comprehensive analysis of different optics and photonics systems in agricultural applications to provide a detail idea of the advanced techniques and their future deployment in agriculture cultivation and harvesting. The review has proposed important and selective suggestions for the further technological development of optics and photonics in future agricultural applications:

- The incorporation of optical sensors into photonics detection techniques that serve as an early warning for drinking water pollution.

- The characterization of canned food or bottled beverages in the NIR (>1100 nm) and MIR wavebands for their optical "fingerprint" that correlates to the quality and food safety level of the product, such as preservatives concentration.

- The characterization on hazardous residual materials in food using optical spectroscopy, Raman spectroscopy and fluorescence.

- The implementation of an agricultural robot to perform better palm oil plantation management, scheduled collection of field latex and weed removal.

- The spectral imaging provides early detection of disease-causing G. boninense in the oil palm.

- Spectroscopy provides moisture content inspection, protein and lipid content detection, as well as improving the rubber vulcanizing process.

- The imaging technique detects external damage or bruises on organic fruits and vegetables. 
Author Contributions: This review paper is mainly scripted by T.J.Y. and K.P.J., L.K.Y. contributed to the technical detail compilation and references, language proficiency and formatting of the manuscript. H.M.A. contributed in the organization of contents for the review paper and the revision of the manuscript. S.T.G.H. offered expertise in relating the optical sensing technique and their applications in the agriculture industry, and also contributed to the checking of language proficiency.

Funding: This research was funded by Universiti Tenaga Nasional Internal Grant with the project code J510050796.

Conflicts of Interest: The authors declare no conflict of interest.

\section{References}

1. National Research Council. Light: Wave-Particle Duality; The National Academic Press: Washington, DC, USA, 2013.

2. An Overview of Optics \& Photonics, Essential Technologies for Our Nation. Available online: https: //www.scribd.com/document/113237529/HLII-Brochure (accessed on 22 November 2018).

3. Brown, L.M.; Pais, A.; Pippard, A.B. A History of Optical and Optoelectronic Physics in the Twentieth Century; American Institute of Physics Press: New York, NY, USA, 1995.

4. Sternberg, E. Photonic Technology and Industrial Policy: U.S. Responses to Technological Change; State University of New York Press: New York, NY, USA, 1992.

5. Sumriddetchkajorn, S. How Optics and Photonics is Simply Applied in Agriculture? In Proceedings of the International Conference on Photonics Solutions (ICPS), Pattaya City, Thailand, 7 June 2013; p. 888311. [CrossRef]

6. Machine Vision in Agricultural Robotics-A Short Overview. Available online: https://pdfs.semanticscholar. org/ef13/5ac11c38022029da4d607343b33abb033758.pdf (accessed on 22 November 2018).

7. Ji, B.; Zhu, W.; Liu, B.; Ma, C.; Li, X. Review of Recent Machine-Vision Technologies in Agriculture. In Proceedings of the Knowledge Acquisition and Modeling, 2009. KAM'09. Second International Symposium, Wuhan, China, 30 November-1 December 2009; pp. 330-334.

8. Ishimwe, R.; Abutaleb, K.; Ahmed, F. Applications of Thermal Imaging in Agriculture-A Review. Adv. Remote Sens. 2014, 3, 128. [CrossRef]

9. Szeliski, R. Computer Vision: Algorithms and Applications; Springer: London, UK, 2010.

10. Gunasekaran, S.; Ding, K. Using computer vision for food quality evaluation. Food Technol. 1994, 6, 151-154.

11. Bhargava, A.; Bansal, A. Fruits and vegetables quality evaluation using computer vision: A review. J. King Saud Univ. Comput. Inf. Sci. 2018. [CrossRef]

12. Raj, M.P.; Swaminarayan, P.R.; Istar, A. Applications of image processing for grading agriculture products. Int. J. Recent Innov. Trends Comput. Commun. 2015, 3, 1194-1201.

13. Mahendran, R.; Jayashree, G.C.; Alagusundaram, K. Application of computer vision technique on sorting and grading of fruits and vegetables. J. Food Process. Technol. 2012, 10, 2157-7110.

14. Nezhad, M.A.K.B.; Massh, J.; Komleh, H.E. Tomato Picking Machine Vision Using with the Open CV's library. In Proceedings of the 7th Iranian Conference on Machine Vision and Image Processing, Tehran, Iran, 16-17 November 2011; pp. 1-5.

15. Bora, G.C.; Pathak, R.; Ahmadi, M.; Mistry, P. Image processing analysis to track colour changes on apple and correlate to moisture content in drying stage. Food Qual. Saf. 2018, 2, 105-110. [CrossRef]

16. Digital Agriculture. Available online: https://sites.tufts.edu/eeseniordesignhandbook/2015/digital-agriculture/ (accessed on 29 April 2019).

17. Nawrocka, A.; Lamorska, L. Advances in Agrophysical Research; IntechOpen: Rijeka, Croatia, 2013.

18. Swinehart, D.F. The Beer-Lambert Law. J. Chem. Educ. 1962, 39, 333. [CrossRef]

19. Animal and Vegetable Fats and Oils-Determination of Anisidine Value. Available online: https://www.iso. org/standard/69593.html (accessed on 22 November 2018).

20. Gray, J.I. Measurement of Lipid Oxidation: A Review. J. Am. Oil Chem. Soc. 1978, 55, 539-546. [CrossRef]

21. Animal and Vegetable Fats and Oils: Determination of Iodine Value. Available online: https://www.researchgate. net/publication/38999704_Animal_and_Vegetable_Fats_and_Oils_Determination_of_Iodine_Value (accessed on 23 November 2018). 
22. Mińkowski, K.; Grześkiewicz, S.; Jerzewska, M.; Ropelewska, M. Characteristic of chemical composition of vegetable oil about high contents of linoleic acids (in Polish). ŻYWNOŚĆ Nauka Technologia Jakość 2010, 73, 146-157.

23. Psomiadou, E.; Tsimidou, M. Pigments in Greek virgin olive oils: Occurrence and levels. J. Sci. Food Agric. 2001, 81, 640-647. [CrossRef]

24. Lakowicz, J.R. Principles of Fluorescence Spectroscopy; Springer: New York, NY, USA, 2006.

25. Albani, J.R. Fluorescence Spectroscopy in Food Analysis. Encycl. Anal. Chem. 2006. [CrossRef]

26. Karoui, R.; Blecker, C. Fluorescence spectroscopy measurement for quality assessment of food systemsA review. Food Bioprocess Technol. 2011, 4, 364-386. [CrossRef]

27. Stuart, B.H. Infrared Spectroscopy: Fundamentals and Applications; John Wiley and Sons Ltd.: Chichester, UK, 2004.

28. Shurvell, H. Spectra-Structure Correlations in the Mid-and Far-Infrared; John Wiley and Sons Ltd.: Chichester, UK, 2006.

29. Li-Chan, E.C.Y.; Ismail, A.A.; Sedman, J.; Voort, F.R. Vibrational Spectroscopy of Food and Food Products; John Wiley and Sons Ltd.: Chichester, UK, 2006.

30. Niaura, G. Raman Spectroscopy in Analysis of Biomolecules; John Wiley and Sons: New York, NY, USA, 2006.

31. Nelson, S.O. Dielectric spectroscopy in agriculture. J. Non-Cryst. Solids 2005, 351, 2940-2944. [CrossRef]

32. Mlynárik, V. Introduction to nuclear magnetic resonance. Anal. Biochem. 2016, 529, 4-9. [CrossRef]

33. Guo, Z.; Huang, W.; Peng, Y.; Chen, Q.; Ouyang, Q.; Zhao, J. Color compensation and comparison of shortwave near infrared and long wave near infrared spectroscopy for determination of soluble solids content of 'Fuji' apple. Postharvest Biol. Technol. 2016, 115, 81-90. [CrossRef]

34. Guo, Z.; Chen, Q.; Chen, L.; Huang, W.; Zhang, C.; Zhao, C. Optimization of Informative Spectral Variables for the Quantification of EGCG in Green Tea Using Fourier Transform Near-Infrared (FT-NIR) Spectroscopy and Multivariate Calibration. Appl. Spectrosc. 2011, 65, 1062-1067. [CrossRef]

35. Qin, J.; Chao, K.; Kim, M.S.; Lu, R.; Burks, T.F. Hyperspectral and multispectral imaging for evaluating food safety and quality. J. Food Eng. 2013, 118, 157-171. [CrossRef]

36. Wu, D.; Sun, D. Advanced applications of hyperspectral imaging technology for food quality and safety analysis and assessment: A review-Part I: Fundamentals. Innov. Food Sci. Emerg. Technol. 2013, 19, 1-14. [CrossRef]

37. Kim, M.S.; Chao, K.; Chan, D.E.; Jun, W.; Lefcourt, A.M.; Delwiche, S.R.; Kang, S.; Lee, K. Line-scan hyperspectral imaging platform for agro-food safety and quality evaluation: System enhancement and characterization. Trans. ASABE 2011, 54, 703-711. [CrossRef]

38. Morris, H.R.; Hoyt, C.C.; Treado, P.J. Imaging spectrometers for fluorescence and Raman microscopy-acousto-optic and liquid-crystal tunable filters. Appl. Spectrosc. 1994, 48, 857-866. [CrossRef]

39. Kise, M.; Park, B.; Heitschmidt, G.W.; Lawrence, K.C.; Windham, W.R. Multispectral imaging system with interchangeable filter design. Comput. Electron. Agric. 2010, 72, 61-68. [CrossRef]

40. Kim, M.S.; Chen, Y.R.; Mehl, P.M. Hyperspectral reflectance and fluorescence imaging system for quality and safety. Trans. ASAE 2001, 44, 721-729.

41. Lu, R. Detection of bruises on apples using near-infrared hyperspectral imaging. Trans. ASAE 2003, 46, 523-530.

42. Manley, M.; Williams, P.; Nilsson, D.; Geladi, P. Near infrared hyperspectral imaging for the evaluation of endosperm texture in whole yellow maize (Zea maize L.) kernels. J. Agric. Food Chem. 2009, 57, 8761-8769. [CrossRef]

43. Litwiller, D. CMOS vs. CCD: Maturing technologies, maturing markets. Photonics Spectra 2005, 39, 54-61.

44. ElMasry, G.; Wang, N.; Vigneault, C. Detecting chilling injury in Red Delicious apple using hyperspectral imaging and neural networks. Postharvest Biol. Technol. 2009, 52, 1-8. [CrossRef]

45. Ngadi, M.O.; Liu, L. Hyperspectral Image Processing Techniques; Academic Press/Elsevier: Cambridge, MA, USA, 2010; pp. 99-127.

46. ElMasry, G.; Wang, N.; ElSayed, A.; Ngadi, M. Hyperspectral imaging for non-destructive determination of some quality attributes for strawberry. J. Food Eng. 2007, 81, 98-107. [CrossRef]

47. Qiao, J.; Wang, N.; Ngadi, M.O.; Gunenc, A.; Monroy, M.; Gariepy, C. Prediction of drip-loss, pH, and color for pork using a hyperspectral imaging technique. Meat Sci. 2007, 76, 1-8. [CrossRef] [PubMed] 
48. Qin, J.W.; Burks, T.F.; Ritenour, M.A.; Bonn, W.G. Detection of citrus canker using hyperspectral reflectance imaging with spectral information divergence. J. Food Eng. 2009, 93, 183-191. [CrossRef]

49. Daugman, J.G. Uncertainty relation for resolution in space, spatial-frequency, and orientation optimized by two-dimensional visual cortical filters. J. Opt. Soc. Am. A Opt. Image Sci. Vis. 1985, 2, 1160-1169. [CrossRef]

50. Lee, K.; Kang, S.; Delwiche, S.R.; Kim, M.S.; Noh, S. Correlation analysis of hyperspectral imagery for multispectral wavelength selection for detection of defects on apples. Sens. Instrum. Food Qual. Saf. 2008, 2, 90-96. [CrossRef]

51. Kim, M.S.; Lefcourt, A.M.; Chao, K.; Chen, Y.R.; Kim, I.; Chan, D.E. Multispectral detection of fecal contamination on apples based on hyperspectral imagery: Part I-Application of visible and near-infrared reflectance imaging. Trans. ASAE 2002, 45, 2027.

52. Park, B.; Lawrence, K.C.; Windham, W.R.; Buhr, R.J. Hyperspectral imaging for detecting fecal and ingesta contaminants on poultry carcasses. In 2001 ASAE Annual Meeting; American Society of Agricultural and Biological Engineers: St. Joseph, MI, USA, 1998. [CrossRef]

53. Bajwa, S.G.; Bajcsy, P.; Groves, P.; Tian, L. Hyperspectral image data mining for band selection in agricultural applications. Trans. ASAE 2004, 47, 895. [CrossRef]

54. Nakariyakul, S.; Casasent, D.P. Hyperspectral waveband selection for contaminant detection on poultry carcasses. Opt. Eng. 2008, 47, 087202.

55. Xing, J.; Guver, D.; Ariana, D.; Lu, R. Determining optimal wavebands using genetic algorithm for detection of internal insect infestation in tart cherry. Sens. Instrum. Food Qual. Saf. 2008, 2, 161-167. [CrossRef]

56. Leiva-Valenzuela, G.A.; Aguilera, J.M. Automatic detection of orientation and diseases in blueberries using image analysis to improve their postharvest storage quality. Food Control 2013, 33, 166-173. [CrossRef]

57. Arakeri, M.P.; Lakshmana. Computer Vision Based Fruit Grading System for Quality Evaluation of Tomato in Agriculture industry. Procedia Comput. Sci. 2016, 79, 426-433. [CrossRef]

58. Sumriddetchkajorn, S.; Somboonkaew, A.; Chanhorm, S. Mobile Device-Based Digital Microscopy for Education, Healthcare, and Agriculture. In Proceedings of the 9th International Conference on Electrical Engineering/Electronics, Computer, Telecommunications and Information Technology (ECTI-CON), Phetchaburi, Thailand, 16-18 May 2012; IEEE: Piscataway, NJ, USA, 2012; pp. 1-4. [CrossRef]

59. Kaur, S.; Pandey, S.; Goel, S. Semi-automatic leaf disease detection and classification system for soybean culture. IET Image Process. 2018, 12, 1038-1048. [CrossRef]

60. Billingsley, J. The Counting of Macadamia Nuts; Research Studies Press Ltd.: Baldock, UK, 2002.

61. Chen, S.W.; Shivakumar, S.S.; Dcunha, S.; Das, J.; Okon, E.; Qu, C.; Taylor, C.J.; Kumar, V. Counting Apples and Oranges with Deep Learning: A Data-Driven Approach. IEEE Robot. Autom. Lett. 2017, 2, 781-788. [CrossRef]

62. Intaravanne, Y.; Sumriddetchkajorn, S.; Nukeaw, J. Cell phone-based two-dimensional spectral analysis for banana ripeness estimation. Sens. Actuators B-Chem. 2012, 168, 390-394. [CrossRef]

63. Marimuthu, S.; Roomi, S.M.M. Particle Swarm Optimized Fuzzy Model for the Classification of Banana Ripeness. IEEE Sens. J. 2017, 17, 4903-4915. [CrossRef]

64. Intaravanne, Y.; Sumriddetchkajorn, S. Android-based rice leaf color analyzer for estimating the needed amount of nitrogen fertilizer. Comput. Electron. Agric. 2015, 116, 228-233. [CrossRef]

65. Sulistyo, S.B.; Woo, W.L.; Dlav, S.S. Regularized Neural Networks Fusion and Genetic Algorithm Based On-Field Nitrogen Status Estimation of Wheat Plants. IEEE Trans. Ind. Inform. 2017, 13, 103-114. [CrossRef]

66. Varith, J.; Hyde, G.; Baritelle, A.; Fellman, J.; Sattabongkot, T. Non-Contact Bruise Detection in Apples by Thermal Imaging. Innov. Food Sci. Emerg. Technol. 2003, 4, 211-218. [CrossRef]

67. Danno, A.; Miyazato, M.; Ishiguro, E. Quality Evaluation of Agricultural Products by Infrared Imaging Method: Grading of Fruits for Bruise and Other Surface Defects. Mem. Fac. Agric. Kagoshima Univ. 1978, 14, 123-138.

68. Oerke, E.; Fröhling, P.; Steiner, U. Thermographic Assessment of Scab Disease on Apple Leaves. Precis. Agric. 2011, 12, 699-715. [CrossRef]

69. Oerke, E.; Steiner, U.; Dehne, H.; Lindenthal, M. Thermal Imaging of Cucumber Leaves Affected by Downy Mildew and Environmental Conditions. J. Exp. Bot. 2006, 57, 2121-2132. [CrossRef] [PubMed]

70. Hellebrand, H.J.; Linke, M.; Beuche, H.; Herold, B.; Geyer, M. Horticultural Products Evaluated by Thermography; The Leibniz Institute for Agricultural Engineering Potsdam-Bornim: Potsdam, Germany, 2000. 
71. Danno, A.; Miyazato, M.; Ishiguro, E. Quality Evaluation of Agricultural Products by Infrared Imaging Method: Maturity Evaluation of Fruits and Vegetables. Mem. Fac. Agric. Kagoshima Univ. 1980, 16, 157-164.

72. Wu, G.; Tan, Y.; Zheng, Y.; Wang, S. Walking Goal Line Detection Based on Machine Vision on Harvesting Robot. In Proceedings of the 2011 Third Pacific-Asia Conference on Circuits, Communications and System (PACCS), Wuhan, China, 17-18 July 2011; IEEE: Piscataway, NJ, USA, 2011; pp. 1-4.

73. Tillett, N.D.; Hague, T.; Miles, S.J. A field assessment of a potential method for weed and crop mapping on the basis of crop planting geometry. Comput. Electron. Agric. 2001, 32, 229-246. [CrossRef]

74. Irie, N.; Taguchi, N.; Horie, T.; Ishimatsu, T. Asparagus harvesting robot coordinated with 3-D vision sensor. In Proceedings of the IEEE International Conference on Industrial Technology (ICIT 2009), Gippsland, VIC, Australia, 10-13 February 2009; IEEE: Piscataway, NJ, USA, 2009; pp. 1-6.

75. Astrand, B.; Baerveldt, A.J. A vision based row-following system for agricultural field machinery. Mechatronics 2005, 15, 251-269. [CrossRef]

76. Songa, X.Y.; Lerova, T.; Vrankena, E.; Maertens, W.; Sonck, B.; Berckmans, D. Automatic detection of lameness in dairy cattle Vision-based trackway analysis in cow's locomotion. Comput. Electron. Agric. 2008, 64, 39-44. [CrossRef]

77. Kane, A.S.; Salierno, J.D.; Gipson, G.T.; Molteno, T.C.A.; Hunter, C. A video-based movement analysis system to quantify behavioural stress responses of fish. Water Res. 2004, 38, 3993-4001. [CrossRef]

78. Baranowski, P.; Mazurek, W.; Wozniak, J.; Majewska, U. Detection of early bruises in apples using hyperspectral data and thermal imaging. J. Food Eng. 2012, 110, 345-355. [CrossRef]

79. Stajnko, D.; Lakota, M.; Hocevar, M. Estimation of Number and Diameter of Apple Fruits in an Orchard during the Growing Season by Thermal Imaging. Comput. Electron. Agric. 2004, 42, 31-42. [CrossRef]

80. Lv, J.; Shen, G.; Ma, Z. Acquisition of Fruit Region in Green Apple Image Based on the Combination of Segmented Regions. In Proceedings of the 2nd International Conference on Image, Vision and Computing, Chengdu, China, 2-4 June 2017.

81. Dunn, M.; Billingsley, J. A Machine Vision System for Surface Texture Measurements of Citrus. In Proceedings of the 11th IEEE conference on Mechatronics and Machine Vision in Practice, Macau, China, 30 November-2 December 2004; pp. 73-76.

82. Ballester, C.; Castel, J.; Jiménez-Bello, M.; Castel, J.; Intrigliolo, D. Thermographic Measurement of Canopy Temperature Is a Useful Tool for Predicting Water Deficit Effects on Fruit Weight in Citrus Trees. Agric. Water Manag. 2013, 122, 1-6. [CrossRef]

83. Bonilla, J.; Prieto, F.; Pérez, C. Mass and Volume Estimation of Passion Fruit using Digital Images. IEEE. Lat. Am. Trans. 2017, 15, 275-282. [CrossRef]

84. Stoll, M.; Schultz, H.R.; Loehnertz, B.B. Exploring the Sensitivity of Thermal Imaging for Plasmopara viticola Pathogen Detection in Grapevines under Different Water Status. Funct. Plant Biol. 2008, 35, 281-288. [CrossRef]

85. Xiao-Lian, L.; Xiao-Rong, L.; Bing-Fu, L. Identification and Location of Picking Tomatoes Based on Machine Vision. In Proceedings of the 2011 International Conference on Intelligent Computation Technology and Automation (ICICTA), Shengzhen, Guangdong, China, 28-29 March 2011; pp. 101-107.

86. Yang, L.; Dickinson, J.; Wu, Q.M.J.; Lang, S. A fruit recognition method for automatic harvesting. In Proceedings of the 14th International Conference on Mechatronics and Machine Vision in Practice (M2VIP2007), Xiamen, China, 3-5 December 2007; pp. 152-157.

87. Vanlinden, V.; Vereycken, R.; Ramon, H.; Baerdemaeker, J.D. Detection technique for tomato bruise damage by thermal imaging. Acta Hortic. 2003, 599, 389-394. [CrossRef]

88. Quan, Q.; Lanlan, T.; Xiaojun, Q.; Kai, J.; Qingchun, F. Selecting Candidate Regions of Clustered Tomato Fruits under Complex Greenhouse Scenes Using RGB-D Data. In Proceedings of the 3rd International Conference on Control, Automation and Robotics, Nagoya, Japan, 22-24 April 2017; pp. 389-393.

89. Sa, I.; Lehnert, C.; McCool, C.; Dayoub, F.; Upcroft, B.; Perez, T. Peduncle Detection of Sweet Pepper for Autonomous Crop Harvesting-Combined Color and 3-D Information. IEEE Robot. Autom. Lett. 2017, 2, 765-772. [CrossRef]

90. Speir, R.A.; Heidekker, M.A. Onion postharvest quality assessment with X-ray computed tomographyA pilot study. IEEE Instrum. Meas. Mag. 2017, 20, 15-19. [CrossRef] 
91. Shi-Gang, C.; Heng, L.; Xing-Li, W.; Yong-Li, Z.; Lin, H. Study on segmentation of lettuce image based on morphological reorganization and watershed algorithm. In Proceedings of the IEEE Chinese Control and Decision Conference (CCDC), IEEE, Shenyang, China, 9-11 June 2018; pp. 6595-6597.

92. Lindenthal, M.; Steiner, U.; Dehne, H.; Oerke, E. Effect of Downy Mildew Development on Transpiration of Cucumber Leaves Visualized by Digital Infrared Thermography. Phytopathology 2005, 95, 233-240. [CrossRef]

93. Oerke, E.; Lindenthal, M.; Fröhling, P.; Steiner, U. Digital Infrared Thermography for the Assessment of Leaf Pathogens. In Proceedings of the 5th European Conference on Precision Agriculture, Uppsala, Sweden, 9-11 June 2005; pp. 91-98.

94. Smith, R.; Barrs, H.; Steiner, J.; Stapper, M. Relationship between Wheat Yield and Foliage Temperature: Theory and Its Application to Infrared Measurements. Agric. For. Meteorol. 1985, 36, 129-143. [CrossRef]

95. Du, W.Y.; Zhang, L.D.; Hu, Z.F.; Shamaila, Z.; Zeng, A.J.; Song, J.L.; Liu, Y.J.; Wolfram, S.; Joachim, M.; He, X.K. Utilization of Thermal Infrared Image for Inversion of Winter Wheat Yield and Biomass. Spectrosc. Spectr. Anal. 2011, 31, 1476-1480.

96. Hu, Z.; Zhang, L.; Wang, Y.; Shamaila, Z.; Zeng, A.; Song, J.; Liu, Y.; Wolfram, S.; Joachim, M.; He, X. Application of BP Neural Network in Predicting Winter Wheat Yield Based on Thermography Technology. Spectrosc. Spectr. Anal. 2013, 33, 1587-1592.

97. Wanjura, D.; Upchurch, D.R. Water Status Response of Corn and Cotton to Altered Irrigation. Irrig. Sci. 2002, 21, 45-55. [CrossRef]

98. Tetila, E.C.; Machado, B.B.; de Souza Belete, N.A.; Guimarães, D.A.; Pistori, H. Identification of Soybean Foliar Diseases Using Unmanned Aerial Vehicle Images. IEEE Geosci. Remote Sens. Lett. 2017, 14, 2190-2194. [CrossRef]

99. Zhou, C.; Yang, G.; Liang, D.; Yang, X.; Xu, B. An Integrated Skeleton Extraction and Pruning Method for Spatial Recognition of Maize Seedlings in MGV and UAV Remote Images. IEEE Geosci. Remote Sens. Lett. 2018, 56, 4618-4632. [CrossRef]

100. Zhang, X.; Qiao, Y.; Meng, F.; Fan, C.; Zhang, M. Identification of Maize Leaf Diseases Using Improved Deep Convolutional Neural Networks. IEEE Access 2018, 6, 30370-30377. [CrossRef]

101. Lu, H.; Cao, Z.; Xiao, Y.; Fang, Z.; Zhu, Y. Toward good practices for fine-grained maize cultivar identification with filter-specific convolutional activations. IEEE Trans. Autom. Sci. Eng. 2018, 15, 430-442. [CrossRef]

102. Padhi, J.; Misra, R.; Payero, J. Estimation of Soil Water Deficit in an Irrigated Cotton Field with Infrared Thermography. Field Crops Res. 2012, 126, 45-55. [CrossRef]

103. Kamtongdee, C.; Sumriddetchkajorn, S.; Chanhorm, S.; Kaewhom, W. Noise reduction and accuracy improvement in optical-penetration-based silkworm gender identification. Appl. Opt. 2015, 54, 1844-1851. [CrossRef]

104. Kranner, I.; Kastbergerb, G.; Hartbauerb, M.; Pritcharda, H.W. Noninvasive Diagnosis of Seed Viability Using Infrared Thermography. Proc. Natl. Acad. Sci. USA 2010, 107, 3912-3917. [CrossRef]

105. Henry, D.; Aubert, H.; Véronèse, T.; Serrano, É. Remote estimation of intra-parcel grape quantity from three-dimensional imagery technique using ground-based microwave FMCW radar. IEEE Instrum. Meas. Mag. 2017, 20, 20-24. [CrossRef]

106. Tosi, M.V.; Ferrante, V.; Mattiello, S.; Canali, E.; Verga, M. Comparison of video and direct observation methods for measuring oral behaviourin veal calves. Ital. J. Anim. Sci. 2006, 5, 19-27. [CrossRef]

107. Dunn, M.; Billingsley, J.; Finch, N. Machine Vision Classification of Animals; Research Studies Press Ltd.: Baldock, UK, 2003.

108. Stien, L.H.; Brafland, S.; Austevollb, I.; Oppedal, F.; Kristiansen, T.S. A video analysis procedure for assessing vertical fish distribution in aquaculture tanks. Aquac. Eng. 2007, 37, 115-124. [CrossRef]

109. Sumriddetchkajorna, S.; Chaitavonb, K.; Intaravanne, Y. Mobile-platform based colorimeter for monitoring chlorine concentration in water. Sens. Actuators B-Chem. 2014, 191, 561-566. [CrossRef]

110. Iqbal, Z.; Bjorklund, R.B. Colorimetric analysis of water and sand samples performed on a mobile phone. Talanta 2011, 84, 1118-1123. [CrossRef] [PubMed]

111. Nagy, A.; Riczu, P.; Tamás, J. Spectral evaluation of apple fruit ripening and pigment contentalteration. Sci. Hortic. 2016, 201, 256-264. [CrossRef]

112. Roy, S.; Anantheswaran, R.C.; Shenk, J.S.; Beelman, R. Determination of moisture content of mushrooms by Vis-NIR spectroscopy. J. Sci. Food Agric. 1993, 63, 355-360. [CrossRef] 
113. Hartmann, R.; Büning-Pfaue, H. NIR determination of potato constituents. Potato Res. 1998, 41, 327-334. [CrossRef]

114. Lee, M.; Hwang, Y.; Lee, J.; Choung, M. The characterization of caffeine and nine individual catechins in the leaves of green tea (Camellia sinensis L.) by near-infrared reflectance spectroscopy. Food Chem. 2014, 158, 351-357. [CrossRef]

115. Sun, X.; Liu, Y.; Li, Y.; Wu, M.; Zhu, D. Simultaneous measurement of brown core and soluble solids content in pear by on-line visible and near infrared spectroscopy. Postharvest Biol. Technol. 2016, 116, 80-87. [CrossRef]

116. Viegas, T.R.; Mata, A.L.M.L.; Duarte, M.M.L.; Lima, K.M.G. Determination of quality attributes in wax jambu fruit using NIRS and PLS. Food Chem. 2016, 190, 1-4. [CrossRef]

117. Gente, R.; Busch, S.F.; Stübling, E.; Schneider, L.M.; Hirschmann, C.B.; Balzer, J.C.; Koch, M. Quality control of sugar beet seeds with THz time-domain spectroscopy. IEEE Trans. Terahertz Sci. Technol. 2016, 6, 754-756. [CrossRef]

118. Nunes, K.M.; Andrade, M.V.O.; Filho, A.M.P.S.; Lasmar, M.C.; Sena, M.M. Detection and characterisation of frauds in bovine meat in natura by non-meat ingredient additions using data fusion of chemical parameters and ATR-FTIR spectroscopy. Food Chem. 2016, 205, 14-22. [CrossRef] [PubMed]

119. ElMasry, G.; Nagai, H.; Moria, K.; Nakazawa, N.; Tsuta, M.; Sugiyama, J.; Okazaki, E.; Nakauchi, S. Freshness estimation of intact frozen fish using fluorescence spectroscopy and chemometrics of excitation-emission matrix. Talanta 2015, 143, 145-156. [CrossRef] [PubMed]

120. Luo, H.; Huang, Y.; Lai, K.; Rasco, B.A.; Fan, Y. Surface-enhanced Raman spectroscopy coupled with gold nanoparticles for rapid detection of phosmet and thiabendazole residues in apples. Food Control 2016, 68, 229-235. [CrossRef]

121. Cozzolino, D. Near infrared spectroscopy as a tool to monitor contaminants in soil, sediments and water-State of the art, advantages and pitfalls. Trends Environ. Anal. Chem. 2016, 9, 1-7. [CrossRef]

122. Nie, P.; Dong, T.; He, Y.; Xiao, S. Research on the effects of drying temperature on nitrogen detection of different soil types by near infrared sensors. Sensors 2018, 18, 391. [CrossRef]

123. Xiao, S.; He, Y.; Dong, T.; Nie, P. Spectral Analysis and Sensitive Waveband Determination Based on Nitrogen Detection of Different Soil Types Using Near Infrared Sensors. Sensors 2018, 18, 523. [CrossRef]

124. Hernández, M.; Valentín, J.L.; López-Manchado, M.A.; Ezquerra, T.A. Influence of the vulcanization system on the dynamics and structure of natural rubber: Comparative study by means of broadband dielectric spectroscopy and solid-state NMR spectroscopy. Eur. Polym. J. 2015, 68, 90-103. [CrossRef]

125. Mahani, R.; Atia, F.; Neklawy, M.M.A.; Fahem, A. Dielectric spectroscopic studies on the water hyacinth plant collected from agriculture drainage. Spectrochim. Acta A Mol. Biomol. Spectrosc. 2016, 162, 81-85. [CrossRef]

126. Jha, S.N.; Narsaiah, K.; Jaiswal, P.; Bhardwaj, R.; Gupta, M.; Kumar, R.; Sharma, R. Nondestructive prediction of maturity of mango using near infrared spectroscopy. J. Food Eng. 2014, 124, 152-157. [CrossRef]

127. Guo, W.; Gu, J.; Liu, D.; Shang, L. Peach variety identification using near-infrared diffuse reflectance spectroscopy. Comput. Electron. Agric. 2016, 123, 297-303. [CrossRef]

128. González-Fernández, A.B.; Rodríguez-Pérez, J.R.; Marabel, M.; Álvarez-Taboada, F. Spectroscopic estimation of leaf water content in commercial vineyards using continuum removal and partial least squares regression. Sci. Hortic. 2015, 188, 15-22. [CrossRef]

129. Schulz, H.; Drews, H.; Quilitzsch, R.; Krüger, H. Application of near infrared spectroscopy for the quantification of quality parameters in selected vegetables and essential oil plants. J. Near Infrared Spectrosc. 1998, 6, A125-A130. [CrossRef]

130. Evans, S.D.; Muir, A.Y. Reflectance Spectrophotometry of Bruising in Potatoes. I. Ultraviolet to Near Infrared. Int. Agrophys. 1999, 13, 203-210.

131. Birth, G.S.; Dull, G.G.; Renfroe, W.T.; Kays, S.J. Nondestructive Spectrophotometric Determination of Dry Matter in Onions. J. Am. Soc. Hortic. Sci. 1985, 110, 297-303.

132. Zhang, C.; Kong, W.; Liu, F.; He, Y. Measurement of aspartic acid in oilseed rape leaves under herbicide stress using near infrared spectroscopy and chemometrics. Heliyon 2016, 2, e00064. [CrossRef]

133. Ambrose, A.; Lohumi, S.; Lee, W.; Cho, B.K. Comparative nondestructive measurement of corn seed viability using Fourier transform near-infrared (FT-NIR) and Raman spectroscopy. Sens. Actuators B-Chem. 2016, 224, 500-506. [CrossRef]

134. Pearson, T.C. Spectral Properties and Effect of Drying Temperature on Almonds with Concealed Damage. LWT-Food Sci. Technol. 1999, 32, 67-72. [CrossRef] 
135. Pearson, T.C. Use of Near Infrared Transmittance to Automatically Detect Almonds with Concealed Damage. LWT-Food Sci. Technol. 1999, 32, 73-78. [CrossRef]

136. Lian, F.; Xu, D.; Fu, M.; Ge, H.; Jiang, Y.; Zhang, Y. Identification of Transgenic Ingredients in Maize Using Terahertz Spectra. IET Nanobiotechnol. 2017, 7, 378-384. [CrossRef]

137. Prasad, T.N.; Adam, S.; Rao, P.V.; Reddy, B.R.; Krishna, T.G. Size dependent effects of antifungal phytogenic silver nanoparticles on germination, growth and biochemical parameters of rice (Oryza sativa L), maize (Zea mays L) and peanut (Arachis hypogaea L). IET Nanobiotechnol. 2016, 11, 277-285. [CrossRef]

138. Sahar, A.; Rahman, U.; Kondjoyan, A.; Portanguen, S.; Dufour, E. Monitoring of thermal changes in meat by synchronous fluorescence spectroscopy. J. Food Eng. 2016, 168, 160-165. [CrossRef]

139. Liu, M.; Yao, L.; Wang, T.; Li, J.; Yu, C. Rapid determination of egg yolk contamination in egg white by VIS spectroscopy. J. Food Eng. 2014, 124, 117-121. [CrossRef]

140. Núñez-Sánchez, N.; Martínez-Marín, A.L.; Polvillo, O.; Fernández-Cabanás, V.M.; Carrizosa, J.; Urrutia, B.; Serradilla, J.M. Near Infrared Spectroscopy (NIRS) for the determination of the milk fat fatty acid profile of goats. Food Chem. 2016, 190, 244-252. [CrossRef] [PubMed]

141. Almoselhy, R.I.M.; Allam, M.H.; El-Kalyoubi, M.H.; El-Sharkawy, A.A. 1H NMR spectral analysis as a new aspect to evaluate the stability of some edible oils. Ann. Agric. Sci. 2014, 59, 201-206. [CrossRef]

142. Mabood, F.; Boqué, R.; Folcarelli, R.; Busto, O.; Jabeen, F.; Al-Harrasi, A.; Hussain, J. The effect of thermal treatment on the enhancement of detection of adulteration in extra virgin olive oils by synchronous fluorescence spectroscopy and chemometric analysis. Spectrochim. Acta Part A: Mol. Biomol. Spectrosc. 2016, 161, 83-87. [CrossRef]

143. Hzounda, J.B.F.; Jazet, P.M.D.; Lazar, G.; Răducanu, D.; Caraman, I.; Bassene, E.; Boyom, F.F.; Lazarca, I.M. Spectral and chemometric analyses reveal antioxidant properties ofessential oils from four Cameroonian Ocimum. Ind. Crops Prod. 2016, 80, 101-108. [CrossRef]

144. Dutta, D.; Das, P.K.; Bhunia, U.K.; Singh, U.; Singh, S.; Sharma, J.R.; Dadhwal, V.K. Retrieval of tea polyphenol at leaf level using spectral transformation and multi-variate statistical approach. Int. J. Appl. Earth Obs. Geoinf. 2015, 36, 22-29. [CrossRef]

145. Marquetti, I.; Link, J.V.; Lemes, A.L.G.; dos Santos Scholz, M.B.; Valderrama, P.; Bona, E. Partial least square with discriminant analysis and near infrared spectroscopy for evaluation of geographic and genotypic origin of arabica coffee. Comput. Electron. Agric. 2016, 121, 313-319. [CrossRef]

146. Bertone, E.; Venturello, A.; Giraudo, A.; Pellegrino, G.; Geobaldo, F. Simultaneous determination by NIR spectroscopy of the roasting degree and Arabica/Robusta ratio in roasted and ground coffee. Food Control 2016, 59, 683-689. [CrossRef]

147. Ayvaz, H.; Sierra-Cadavid, A.; Aykas, D.P.; Mulqueeney, B.; Sullivan, S.; Rodriguez-Saona, L.E. Monitoring multicomponent quality traits in tomato juice using portable mid-infrared (MIR) spectroscopy and multivariate analysis. Food Control 2016, 66, 79-86. [CrossRef]

148. Ye, M.; Gao, Z.; Li, Z.; Yuan, Y.; Yue, T. Rapid detection of volatile compounds in apple wines using FT-NIR spectroscopy. Food Chem. 2016, 190, 701-708. [CrossRef] [PubMed]

149. Kim, D.; Cho, B.; Lee, S.H.; Kwon, K.; Park, E.S.; Lee, W. Application of Fourier transform-mid infrared reflectance spectroscopy for monitoring Korean traditional rice wine 'Makgeolli' fermentation. Sens. Actuators B-Chem. 2016, 230, 753-760. [CrossRef]

150. Fortier, C.; Rodgers, J. Preliminary Examinations for the Identification of U.S. Domestic and International Cotton Fibers by Near-Infrared Spectroscopy. Fibers 2014, 2, 264-274. [CrossRef]

151. Liu, Y.; Delhom, C.; Campbell, B.T.; Martin, V. Application of near infrared spectroscopy in cotton fiber micronaire measurement. Inf. Process. Agric. 2016, 3, 30-35. [CrossRef]

152. Rolere, S.; Liengprayoon, S.; Vaysse, L.; Sainte-Beuve, J.; Bonfils, F. Investigating natural rubber composition with Fourier Transform Infrared (FT-IR) spectroscopy: A rapid and non-destructive method to determine both protein and lipid contents simultaneously. Polym. Test. 2015, 43, 83-93. [CrossRef]

153. Musto, P.; Larobina, D.; Cotugno, S.; Straffi, P.; Florio, G.D.; Mensitieri, G. Confocal Raman imaging, FTIR spectroscopy and kinetic modelling of the zinc oxide/stearic acid reaction in a vulcanizing rubber. Polymer 2013, 54, 685-693. [CrossRef]

154. Yrieix, M.; Cruz-Boisson, F.D.; Majesté, J. Rubber/silane reaction sand grafting rates investigated by liquid-state NMR spectroscopy. Polymer 2016, 87, 90-97. [CrossRef] 
155. Suchat, S.; Theanjumol, P.; Karrila, S. Rapid moisture determination for cup lump natural rubber by near infrared spectroscopy. Ind. Crops Prod. 2015, 76, 772-780. [CrossRef]

156. Avinash, B.; Venu, R.; Prasad, T.N.; Rao, K.S.; Srilatha, C. Synthesis and characterisation of neem leaf extract, 2, 3-dehydrosalanol and quercetin dihydrate mediated silver nano particles for therapeutic applications. IET Nanobiotechnol. 2016, 11, 383-389. [CrossRef]

157. Cécillon, L.; Barthès, B.; Gomez, C.; Ertlen, D.; Génot, V.; Hedde, M.; Stevens, A.; Brun, J. Assessment and monitoring of soil quality using near infrared reflectance spectroscopy (NIRS). Eur. J. Oral Sci. 2009, 60, 770-784.

158. Zhang, Y.; Li, M.; Zheng, L.; Zhao, Y.; Pei, X. Soil nitrogen content forecasting based on real-time NIR spectroscopy. Comput. Electron. Agric. 2016, 124, 29-36. [CrossRef]

159. Ludwig, B.; Linsler, D.; Höper, H.; Schimdt, H.; Piepho, H.; Vohland, M. Pitfalls in the use of middle-infrared spectroscopy: Representativeness and ranking criteria for the estimation of soil properties. Geoderma 2016, 268, 165-175. [CrossRef]

160. Wang, Y.; Jiang, F.; Gupta, B.B.; Rho, S.; Liu, Q.; Hou, H.; Jing, D.; Shen, W. Variable Selection and Optimization in Rapid Detection of Soybean Straw Biomass Based on CARS. Cellulose 2018, 144, 28-51. [CrossRef]

161. Symonds, P.; Paap, A.; Alameh, K.; Rowe, J.; Miller, C. A real-time plant discrimination system utilising discrete reflectance spectroscopy. Comput. Electron. Agric. 2015, 117, 57-69. [CrossRef]

162. Bennedsen, B.S.; Peterson, D.L.; Tabb, A. Identifying defects in images of rotating apples. Comput. Electron. Agric. 2005, 48, 92-102. [CrossRef]

163. Gowen, A.A.; O’Donnell, C.P.; Taghizadeh, M.; Cullen, P.J.; Frias, J.M.; Downey, G. Hyperspectral imaging combined with principal component analysis for bruise damage detection on white mushrooms (Agaricus bisporus). J. Chemom. 2008, 22, 259-267. [CrossRef]

164. Lleo, L.; Barreiro, P.; Ruiz-Altisent, M.; Herrero, A. Multispectral images of peach related to firmness and maturity at harvest. J. Food Eng. 2009, 93, 229-235. [CrossRef]

165. Zhang, C.; Guo, C.; Liu, F.; Kong, W.; He, Y.; Lou, B. Hyperspectral imaging analysis for ripeness evaluation of strawberry with support vector machine. J. Food Eng. 2016, 179, 11-18. [CrossRef]

166. Polder, G.; van der Heijden, G.W.; Young, I.T. Spectral image analysis for measuring ripeness of tomatoes. Trans. ASAE 2002, 45, 1155-1161. [CrossRef]

167. Hahn, F. Multi-spectral prediction of unripe tomatoes. Biosyst. Eng. 2002, 81, 147-155. [CrossRef]

168. Chen, J.; Cai, F.; He, R.; He, S. Experimental Demonstration of Remote and Compact Imaging Spectrometer Based on Mobile Devices. Sensors 2018, 18, 1989. [CrossRef] [PubMed]

169. Lu, R.; Peng, Y. Development of a multispectral imaging prototype for real-time detection of apple fruit firmness. Opt. Eng. 2007, 46, 123201.

170. Baiano, A.; Terracone, C.; Peri, G.; Romaniello, R. Application of hyperspectral imaging for prediction of physico-chemical and sensory characteristics of table grapes. Comput. Electron. Agric. 2012, 87, 142-151. [CrossRef]

171. Zhao, J.; Chen, Q.; Cai, J.; Ouyang, Q. Automated tea quality classification by hyperspectral imaging. Appl. Opt. 2009, 48, 3557-3564. [CrossRef] [PubMed]

172. Qin, J.; Burks, T.F.; Zhao, X.; Niphadkar, N.; Ritenour, M.A. Development of a two-band spectral imaging system for real-time citrus canker detection. J. Food Eng. 2012, 108, 87-93. [CrossRef]

173. Wang, W.; Li, C.; Tollner, E.W.; Gitaitis, R.D.; Rains, G.C. Shortwave infrared hyperspectral imaging for detecting sour skin (Burkholderia cepacia)-infected onions. J. Food Eng. 2012, 109, 38-48. [CrossRef]

174. Chao, K.; Mehl, P.M.; Chen, Y.R. Use of hyper- and multi-spectral imaging for detection of chicken skin tumors. Appl. Eng. Agric. 2002, 18, 113. [CrossRef]

175. Kumar, A.; Manjunath, K.R.; Meenakshi; Bala, R.; Sud, R.K.; Singh, R.D.; Panigrahy, S. Field hyperspectral data analysis for discriminating spectral behavior of tea plantations under various management practices. Int. J. Appl. Earth Obs. Geoinf. 2013, 23, 352-359. [CrossRef]

176. Martins, G.D.; Galo, M.D.L.B.T.; Vieira, B.S. Detecting and Mapping Root-Knot Nematode Infection in Coffee Crop Using Remote Sensing Measurements. IEEE J. Sel. Top. Appl. Earth Obs. Remote Sens. 2017, 10, 5395-5403. [CrossRef]

177. Leiva-Valenzuela, G.A.; Lu, R.; Aguilera, J.M. Prediction of firmness and soluble solids content of blueberries using hyperspectral reflectance imaging. J. Food Eng. 2013, 115, 91-98. [CrossRef] 
178. Qin, J.; Lu, R. Measurement of the absorption and scattering properties of turbid liquid foods using hyperspectral imaging. Appl. Spectrosc. 2007, 61, 388-396. [CrossRef] [PubMed]

179. Gila, D.M.M.; Marchal, P.C.; García, J.G.; Ortega, J.G. On-line system based on hyperspectral information to estimate acidity, moisture and peroxides in olive oil samples. Comput. Electron. Agric. 2015, 116, 1-7. [CrossRef]

180. Keresztes, J.C.; Goodarzi, M.; Saeys, W. Real-time pixel based early apple bruise detection using short wave infrared hyperspectral imaging in combination with calibration and glare correction techniques. Food Control 2016, 66, 215-226. [CrossRef]

181. Baranowski, P.; Mazurek, W.; Pastuszka-Woźniak, J. Supervised classification of bruised apples with respect to the time after bruising on the basis of hyperspectral imaging data. Postharvest Biol. Technol. 2013, 86, 249-258. [CrossRef]

182. Kim, M.S.; Lee, K.; Chao, K.; Lefcourt, A.M.; Jun, W.; Chan, D.E. Multispectral line-scan imaging system for simultaneous fluorescence and reflectance measurements of apples: Multitask apple inspection system. Sens. Instrum. Food Qual. Saf. 2008, 2, 123-129. [CrossRef]

183. Lu, R.; Peng, Y. Hyperspectral scattering for assessing peach fruit firmness. Biosyst. Eng. 2006, 93, $161-171$. [CrossRef]

184. Rajkumar, P.; Wang, N.; EImasry, G.; Raghavan, G.S.V.; Gariepy, Y. Studies on banana fruit quality and maturity stages using hyperspectral imaging. J. Food Eng. 2012, 108, 194-200. [CrossRef]

185. Leiva-Valenzuela, G.A.; Lu, R.; Aguilera, J.M. Assessment of internal quality of blueberries using hyperspectral transmittance and reflectance images with whole spectra or selected wavelengths. Innov. Food Sci. Emerg. Technol. 2014, 24, 2-13. [CrossRef]

186. Qin, J.; Lu, R. Detection of pits in tart cherries by hyperspectral transmission imaging. Trans. ASAE 2005, 48, 1963-1970. [CrossRef]

187. Liu, Y.; Chen, Y.R.; Wang, C.; Chan, D.E.; Kim, M.S. Development of a simple algorithm for the detection of chilling injury in cucumbers from visible/near-infrared hyperspectral imaging. Appl. Spectrosc. 2005, 59, 78-85. [CrossRef]

188. Hernández-Hierro, J.M.; Esquerre, C.; Valverde, J.; Villacreces, S.; Reilly, K.; Gaffne, M.; González-Miret, M.L.; Heredia, F.J.; O'Donnell, C.P.; Downey, G. Preliminary study on the use of near infrared hyperspectral imaging for quantitation and localisation of total glucosinolates in freeze-dried broccoli. J. Food Eng. 2014, 126, 107-112. [CrossRef]

189. Trong, D.; Nyugen, N.; Tsuta, M.; Nicolaï, B.M.; Baerdemaeker, J.D.; Saeys, W. Prediction of optimal cooking time for boiled potatoes by hyperspectral imaging. J. Food Eng. 2011, 105, 617-624. [CrossRef]

190. Onoyama, H.; Ryu, C.; Suguri, M.; Iida, M. Estimation of Nitrogen Contents in Rice Plant at the Panicle Initiation Stage Using Ground-Based Hyperspectral Remote Sensing. IFAC Proc. Vol. 2010, 43, 166-171. [CrossRef]

191. Onoyama, H.; Ryu, C.; Suguri, M.; Iida, M. Potential of Hyperspectral Imaging for Constructing a Year-invariant Model to Estimate the Nitrogen Content of Rice Plants at the Panicle Initiation Stage. IFAC Proc. Vol. 2013, 46, 219-224. [CrossRef]

192. Suwansukho, K.; Sumriddetchkajorn, S.; Buranasiri, P. Demonstration of a single-wavelength spectral-imaging- based Thai jasmine rice identification. Appl. Opt. 2011, 50, 4024-4030. [CrossRef]

193. Zhang, H.; Paliwal, J.; Jayas, D.S.; White, N.D.G. Classification of fungal infected wheat kernels using near-infrared reflectance hyperspectral imaging and support vector machine. Trans. ASABE 2007, 50, 1779-1785. [CrossRef]

194. Xing, J.; Huang, P.; Symons, S.; Shahin, M.; Hatcher, D. Using a short wavelength infrared (SWIR) hyperspectral imaging system to predict alpha amylase activity in individual Canadian western wheat kernels. Sens. Instrum. Food Qual. Saf. 2009, 3, 211. [CrossRef]

195. Patrick, A.; Pelham, S.; Culbreath, A.; Holbrook, C.C.; De Godoy, I.J.; Li, C. High throughput phenotyping of tomato spot wilt disease in peanuts using unmanned aerial systems and multispectral imaging. IEEE Instrum. Meas. Mag. 2017, 20, 4-12. [CrossRef]

196. Weinstock, B.A.; Janni, J.; Hagen, L.; Wright, S. Prediction of oil and oleic acid concentrations in individual corn (Zea mays L.) kernels using near-infrared reflectance hyperspectral imaging and multivariate analysis. Appl. Spectrosc. 2006, 60, 9-16. [CrossRef] [PubMed] 
197. Yao, H.; Hruska, Z.; Kincaid, R.; Brown, R.; Cleveland, T.; Bhatnagar, D. Correlation and classification of single kernel fluorescence hyperspectral data with aflatoxin concentration in corn kernels inoculated with Aspergillus flavus spores. Food Addict. Contam. Part A Chem. 2010, 27, 701-709. [CrossRef] [PubMed]

198. Chao, K.; Chen, Y.R.; Hruschka, W.R.; Park, B. Chicken heart disease characterization by multi-spectral imaging. Appl. Eng. Agric. 2001, 17, 99. [CrossRef]

199. Kise, M.; Park, B.; Lawrence, K.C.; Windham, W.R. Design and calibration of a dual-band imaging system. Sens. Instrum. Food Qual. Saf. 2007, 1, 113-121. [CrossRef]

200. Chao, K.; Yang, C.C.; Kim, M.S.; Chan, D.E. High throughput spectral imaging system for wholesomeness inspection of chicken. Appl. Eng. Agric. 2008, 24, 475-485. [CrossRef]

201. Naganathan, G.K.; Grimes, L.M.; Subbiah, J.; Calkins, C.R.; Samal, A.; Meyer, G.E. Visible/near-infrared hyperspectral imaging for beef tenderness prediction. Comput. Electron. Agric. 2008, 64, 225-233. [CrossRef]

202. Peng, Y.; Zhang, J.; Wang, W.; Li, Y.; Wu, J.; Huang, H.; Gao, X.; Jiang, W. Potential prediction of the microbial spoilage of beef using spatially resolved hyperspectral scattering profiles. J. Food Eng. 2011, 102, 163-169. [CrossRef]

203. Kamruzzaman, M.; ElMasry, G.; Sun, D.; Allen, P. Application of NIR hyperspectral imaging for discrimination of lamb muscles. J. Food Eng. 2011, 104, 332-340. [CrossRef]

204. Tao, F.; Peng, Y. A method for nondestructive prediction of pork meat quality and safety attributes by hyperspectral imaging technique. J. Food Eng. 2014, 126, 98-106. [CrossRef]

205. Barbin, D.; Elmasry, G.; Sun, D.; Allen, P. Near-infrared hyperspectral imaging for grading and classification of pork. Meat Sci. 2012, 90, 259-268. [CrossRef] [PubMed]

206. ElMasry, G.; Wold, J.P. High-speed assessment of fat and water content distribution in fish fillets using online imaging spectroscopy. J. Agric. Food Chem. 2008, 56, 7672-7677. [CrossRef] [PubMed]

207. Sivertsen, A.H.; Chu, C.K.; Wang, L.C.; Godtliebsen, F.; Heia, K.; Nilsen, H. Ridge detection with application to automatic fish fillet inspection. J. Food Eng. 2009, 90, 317-324. [CrossRef]

208. Wu, D.; Sun, D. Potential of time series-hyperspectral imaging (TS-HSI) for non-invasive determination of microbial spoilage of salmon flesh. Talanta 2013, 111, 39-46. [CrossRef]

209. Wu, D.; Shi, H.; Wang, S.; Hea, Y.; Bao, Y.; Liu, K. Rapid prediction of moisture content of dehydrated prawns using online hyperspectral imaging system. Anal. Chim. Acta 2012, 726, 57-66. [CrossRef] [PubMed]

210. Wu, D.; Shi, H.; He, Y.; Yu, X.; Bao, Y. Potential of hyperspectral imaging and multivariate analysis for rapid and non-invasive detection of gelatin adulteration in prawn. J. Food Eng. 2013, 119, 680-686. [CrossRef]

211. Lim, J.; Kim, G.; Mo, C.; Kim, M.S.; Chao, K.; Qin, J.; Fu, X.; Baek, I.; Cho, B. Detection of melamine in milk powders using near-infrared hyperspectral imaging combined with regression coefficient of partial least square regression model. Talanta 2016, 151, 183-191. [CrossRef]

212. Qin, J.; Chao, K.; Kim, M.S. Raman chemical imaging system for food safety and quality inspection. Trans. ASABE 2010, 53, 1873-1882. [CrossRef]

213. Deng, S.; Xu, Y.; Li, X.; He, Y. Moisture content prediction in tealeaf with near infrared hyperspectral imaging. Comput. Electron. Agric. 2015, 118, 38-46. [CrossRef]

214. Wu, D.; Yang, H.; Chen, X.; He, Y.; Li, X. Application of image texture for the sorting of tea categories using multi-spectral imaging technique and support vector machine. J. Food Eng. 2008, 88, 474-483. [CrossRef]

215. Chemura, A.; Mutanga, O.; Odindi, J. Empirical Modeling of Leaf Chlorophyll Content in Coffee (Coffea Arabica) Plantations with Sentinel-2 MSI Data: Effects of Spectral Settings, Spatial Resolution, and Crop Canopy Cover. IEEE J. Sel. Top. Appl. Earth Obs. Remote Sens. 2017, 10, 5541-5550. [CrossRef]

216. Heibati, M.; Stedmon, C.A.; Stenroth, K.; Rauch, S.; Toljander, J.; Säve-Söderbergh, M.; Murphy, K.R. Assessment of drinking water quality at the tap using fluorescence spectroscopy. Water Res. 2017, 125, 1-10. [CrossRef]

217. Sorensen, J.P.R.; Vivanco, A.; Ascott, M.J.; Gooddy, D.C.; Lapworth, D.J.; Read, D.S.; Rushworth, C.M.; Bucknall, J.; Herbert, K.; Karapanos, I.; et al. Online fluorescence spectroscopy for the real-time evaluation of the microbial quality of drinking water. Water Res. 2018, 137, 301-309. [CrossRef] [PubMed]

218. Højris, B.; Christensen, S.C.B.; Albrechtsen, H.J.; Smith, C.; Dahlqvist, M. A novel, optical, on-line bacteria sensor for monitoring drinking water quality. Sci. Rep. 2016, 6, 23935. [CrossRef] [PubMed] 
219. Mignani, A.G.; Ciaccheri, L.; Ottevaere, H.; Thienpont, H.; Conte, L.; Marega, M.; Cichelli, A.; Attilio, C.; Cimato, A. Visible and near-infrared absorption spectroscopy by an integrating sphere and optical fibers for quantifying and discriminating the adulteration of extra virgin olive oil from Tuscany. Anal. Bioanal. Chem. 2011, 399, 1315-1324. [CrossRef]

220. Woodcock, T.; Downey, G.; O'Donnel, C. Near infrared spectral fingerprinting for confirmation of claimed PDO provenance of honey. Food Chem. 2009, 114, 742-746. [CrossRef]

221. Li, X.; He, Y.; Wu, C.; Sun, D.W. Non desctructive measurement and fingerprint analysis of soluble content of tea soft drink based on Vis/NIR spectroscopy. J. Food Eng. 2007, 82, 316-323. [CrossRef]

222. Fagan, C.C.; Castillo, M.; O’Donnel, C.P.; Callaghan, D.J.; Payne, F.A. Online prediction of cheese making indices using backscatter of near infrared light. Int. Dairy J. 2008, 18, 120-128. [CrossRef]

223. Egidio, V.D.; Oliveri, P.; Woodcock, T.; Downey, G. Confirmation of brand identity in foods by near infrared transflectance spectroscopy using classification and class-modelling chemometric techniques-The example of a Belgian beer. Food Res. Int. 2011, 44, 544-549. [CrossRef]

224. Leong, Y.S.; Ker, P.J.; Jamaludin, M.Z.; Nomanbhay, S.M.; Ismail, A.; Abdullah, F.; Looe, H.M.; Shukri, C.N.S. New near-infrared absorbance peak for inhibitor content detection in transformer insulating oil. Sens. Actuators B Chem. 2018, 266, 577-582. [CrossRef]

225. Li, T.L.; Chung-Wang, Y.J.; Shih, Y.C. Determination and confirmation of chloramphenicol residues in swine muscle and liver. J. Food Sci. 2002, 67, 21-28. [CrossRef]

226. Overview: Malaysian Agricultural Biotechnology. BiotechCorp, 2009. Available online: http://www. bioeconomycorporation.my/wp-content/uploads/2011/11/publications/White_Paper_Agricultural.pdf (accessed on 25 November 2018).

227. Ahmad, T.T.M.A.; Suntharalingam, C. Transformation and Economic Growth of the Malaysian Agricultural Sector. Econ. Technol. Manag. Rev. 2009, 4, 1-10.

228. Matahir, H. The Empirical Investigation of the Nexus between Agricultural and Industrial Sectors in Malaysia. Int. J. Bus. Manag. Soc. Res. 2012, 3, 225-231.

229. Onn, F.C. Small and Medium Industries in Malaysia: Economic Efficiency and Entrepreneurship. Dev. Econ. 1990, 28, 152-179.

230. Rahman, A.A.Z. Economic Reforms and Agricultural Development in Malaysia. ASEAN Econ. Bull. 1998, 15, 59-76. [CrossRef]

231. Shaffril, M.H.A.; Asmuni, A.; Ismail, A. The Ninth Malaysian Plan and Agriculture Extension Officer Competency: A Combination for Intensification of Paddy Industry in Malaysian. J. Int. Soc. Res. 2010, 3, 450-457.

232. Eleventh Malaysia Plan 2016-2020 Anchoring Growth on People; Percetakan Nasional Malaysia: Kuala Lumpur, Malaysia, 2015; Available online: https://www.mkma.org/Notice\%20Board/2015/MP11Book.pdf (accessed on 25 November 2018).

233. Murad, M.W.; Mustapha, N.H.; Siwar, C. Review of Agricultural Policies with Regards to Sustainability. Am. J. Environ. Sci. 2008, 4, 608-614. [CrossRef]

234. Tenth Malaysia Plan 2011-2015; Percetakan Nasional Malaysia: Kuala Lumpur, Malaysia, 2010. Available online: http://www.pmo.gov.my/dokumenattached/RMK/RMK10_E.pdf (accessed on 25 November 2018).

235. Tagoe, S.M.A.; Dickinson, M.J.; Apetorgbor, M.M. Factors influencing quality of palm oil produced at the cottage industry level in Ghana. Int. Food Res. J. 2012, 19, 271-278.

236. Hushiarian, R.; Yusof, N.A.; Dutse, S.W. Detection and control of Ganoderma boninense: Strategies and perspectives. SpringerPlus 2013, 2, 555. [CrossRef] [PubMed]

237. Lelong, C.C.; Roger, J.; Brégand, S.; Dubertret, F.; Lanore, M.; Sitorus, N.; Raharjo, D.; Caliman, J. Evaluation of Oil-palm fungal disease infestation with canopy hyperspectral reflectance data. Sensors 2010, 10, 734-747. [CrossRef] [PubMed]

(C) 2019 by the authors. Licensee MDPI, Basel, Switzerland. This article is an open access article distributed under the terms and conditions of the Creative Commons Attribution (CC BY) license (http://creativecommons.org/licenses/by/4.0/). 